\title{
Dynamics of sand and mud mixtures: A multiprocess-based modelling strategy
}

\author{
Pierre Le Hir ${ }^{a,}{ }^{*}$, Florence Cayocca ${ }^{a}$ and Benoît Waeles ${ }^{1, a}$
}

a IFREMER, Laboratoire DYNECO-PHYSED, BP 70, 29280 Plouzané, France

${ }^{1}$ Present address: CREOCEAN, ZI Chef de Baie, 17000 La Rochelle, France.

*Corresponding author : P. Le Hir, email address : plehir@ifremer.fr

\begin{abstract}
:
Mixed sediments are constituted of cohesive and non-cohesive materials with distinct behaviours that numerical models traditionally manage separately. This paper first introduces a rapid state of the Art in sediment transport modelling in order to point out the specific requirements for process-based models applied to mixed sediments.

Based on a preliminary study by Waeles et al. (2007), which showed the validity of the advection approach to compute fine sand transport, a complete modelling strategy is described: it is applied to the suspended transport of sand and mud mixtures, and accounts for consolidation of mixed sediments. Special care is paid to the realistic representation of the structure and density of sand and mud mixtures, and to the segregation in consolidating sediment layers.

The model state variables are the different classes of particles, generally classified according to their size, and grouped into categories that are either transported as bedload or in suspension. The bed is described as thin layers characterised by a distribution of these classes. The erosion law for fine sands and for sand and mud mixtures is a function of the excess shear stress calibrated against measurements in a small flume. The transition between cohesive and non-cohesive behaviours is parameterised through a critical mud fraction that depends on the sand grain size: the coarser the sand, the higher the mud content before the sediment becomes cohesive. The consolidation module is based on Gibson equation formulated for each class, and modified to account for segregation. Constitutive relationships are calibrated by means of laboratory settling tests. In the deposition module, new deposits may be managed in different ways (creation of a new layer or integration into the existing surficial layer) depending on the mud fraction and its relative concentration. When deposited material is mixed with the surficial sediment, pores between coarser particles are first filled up with finer particles before increasing the layer thickness.

The new modelling frame has first been used to simulate laboratory settling tests with mixed sediments. When the initial mixture density is low, sand particles can settle through the mud and form a dense sandy layer on the bottom. In a second application, the model is used to describe sorting processes when tidal currents re-suspend a sand and mud mixture. A sand layer is then likely to form within the sediment, while the surficial layers are muddier. A dynamic bed armouring process is shown: although sand is easily resuspended, eroded grains in the sand layer settle rapidly, reducing the erosion of underlying sediment. Resulting suspended sediment concentration is strongly reduced, as well as sediment fluxes. The application demonstrates the model ability to simulate layering processes and time-variations of sediment erodibility.

\section{Research highlights}

- We present a multilayered mixed sediment (sand+mud) model. The model respects concentrations for sorted and mixed sediments, it accounts for consolidation. Sand segregation is simulated. A dynamic bed armouring process is suggested: rapid settling of sand protects underlying sediment.
\end{abstract}




\title{
Dynamics of sand and mud mixtures: a multiprocess-based modelling strategy
}

\author{
Pierre LE HIR ${ }^{1}$, Florence CAYOCCA ${ }^{1}$ and Benoît WAELES ${ }^{1,2}$
}

${ }^{1}$ IFREMER, Laboratoire DYNECO-PHYSED, BP 70, 29280 Plouzané, France.

Email: plehir@ifremer.fr \& fcayocca@ifremer.fr

${ }^{2}$ present address: CREOCEAN, ZI Chef de Baie, 17000 La Rochelle, France.

Email:waeles@creocean.fr

Keywords: sediment transport modelling, mixed sediment, sand, mud, suspension, consolidation.

\begin{abstract}
Mixed sediments are constituted of cohesive and non-cohesive materials with distinct behaviours that numerical models traditionally manage separately. This paper first introduces a rapid state of the Art in sediment transport modelling in order to point out the specific requirements for processbased models applied to mixed sediments. .

Based on a preliminary study by Waeles et al. (2007) which showed the validity of the advection approach to compute fine sand transport, a complete modelling strategy is described: it is applied to the suspended transport of sand and mud mixtures, and accounts for consolidation of mixed sediments. Special care is paid to the realistic representation of the structure and density of sand and mud mixtures, and to the segregation in consolidating sediment layers.
\end{abstract}


The model state variables are the different classes of particles, generally classified according to their size, and grouped into categories that are either transported as bedload or in suspension. The bed is described as thin layers characterized by a distribution of these classes. The erosion law for fine sands and for sand and mud mixtures is a function of the excess shear stress calibrated against measurements in a small flume. The transition between cohesive and non cohesive behaviours is parameterised through a critical mud fraction that depends on the sand grain size: the coarser sand, the higher mud content before the sediment becomes cohesive. The consolidation module is based on Gibson equation formulated for each class, and modified to account for segregation. Constitutive relationships are calibrated by means of laboratory settling tests. In the deposition module, new deposits may be managed in different ways (creation of a new layer or integration into the existing surficial layer) depending on the mud fraction and its relative concentration. When deposited material is mixed with the surficial sediment, pores between coarser particles are first filled up with finer particles before increasing the layer thickness.

The new modelling frame has first been used to simulate laboratory settling tests with mixed sediments. When the initial mixture density is low, sand particles can settle through the mud and form a dense sandy layer on the bottom. In a second application, the model is used to describe sorting processes when tidal currents re-suspend a sand and mud mixture. A sand layer is then likely to form within the sediment, while the surficial layers are muddier. A dynamic bed armouring process is shown: although sand is easily resuspended, eroded grains in the sand layer settle rapidly, reducing the erosion of underlying sediment. Resulting suspended sediment concentration is strongly reduced, as well as sediment fluxes. The application demonstrates the model ability to simulate layering processes and time-variations of sediment erodibility.

\section{1- Introduction and background}


When dealing with sediment dynamics for environmental purposes, particularly in semi-enclosed areas such as coastal embayments or estuaries, it is generally necessary to consider both sandy and muddy sediments. Sand and mud can be intimately mixed, may exhibit a horizontal gradient (e.g. resulting from gradients in the current or wave patterns), or can be layered in the bed, and witness the history of forcing events. Numerical models therefore have to account for the simultaneous transport of sand and mud in order to simulate sediment dynamics in those environments. However, for historical, cultural and technical reasons, modelling techniques in sediment transport simulations are classically split into two classes:

- $\quad$ for non cohesive sediment (sand and gravel), sediment evolution is computed by solving a continuity equation (Exner equation) where erosion or deposition result from the divergence of a transport capacity related to the hydrodynamic regime; this method is suitable when equilibrium is reached rapidly, which is the case for sediment with high settling velocity;

- for fine sand and cohesive sediments that are mostly transported in suspension, an advection/diffusion equation is solved (either depth-integrated or not) and the sediment evolution is straightforwardly deduced from erosion and deposition rates.

Reasons for this division are manifold. They partly result from the early interest that engineers showed for grain dynamics in rivers and on beaches, which they investigated through flume experiments leading to empirical formulations, whereas fine sediments have been dealt with later, when environmental questions arose and at a time when computers allowed to numerically solve the advection equation.

The use of either technique (divergence of transport capacities versus sediment advection/diffusion) raises difficulties when applied to the sediment category for which it was not developed: a) equilibrium conditions are rarely met in the case of cohesive sediment, b) the horizontal velocity of large and dense particles is poorly described, which makes the use of an advection equation inappropriate in the case of bedload transport. 
One of the first models that accounted for the simultaneous transport of cohesive and non-cohesive sediments was proposed by Chesher and Ockenden (1997), followed by a few others (e.g. Van Ledden, 2002; Waeles et al., 2007; Sanford, 2008). These attempts differ in several approaches that can be classified as follows:

- the sand transport mode, either considered as bedload or suspended transport,

- the possible splitting of sand types into several (size) classes,

- processes in the bed and the possible definition of an "active layer”,

- management of bed/water exchanges,

- $\quad$ simulation of consolidation processes.

Chesher and Ockenden (1997) solve transport equations for sand and mud concentrations, with contrasted settling velocities. Interactions are accounted for by considering the same critical erosion shear stress for sand and mud, which depends on the mud content in the bed. Since the critical erosion shear stress is supposed to increase for mixed sediments, these authors obtain a strong reduction in the entrainment of both types of sediment when interactions are included. No bed structure is considered, but the vertically averaged bed composition varies in time.

Van Ledden (2002) and van Ledden et al. (2004a) also consider two sediment fractions (sand and mud), both transported in suspension, and distinguish two regimes in the formulation of erosion, according to the mud content in the surficial sediment: in the non cohesive regime, the erosion flux of sand is expressed as a function of an equilibrium concentration and the erosion flux of mud follows the so-called Partheniades-Ariathurai law, corrected by the mud fraction. In the cohesive regime, the Partheniades-Ariathurai law is used for both classes (with their respective fractions, but the erosion rate and the critical shear stress for erosion are those related to mud). Following Armanini (1995), van Ledden (2002) assumes that the bed composition (i.e. the sand content) satisfies an advection-diffusion equation in a Lagrangian vertical coordinate within the bed. He uses a mixing coefficient decreasing with depth and proportional to the friction velocity and the grain size. No consolidation is accounted for, but bioturbation can be simulated through an additional mixing. This 3D process-based sand-mud model was interestingly applied to morphological simulations in a real case: running the model at large time scales allowed to 
simulate long term changes of the surficial sediment nature, over several decades (van Ledden et al., 2006).

Waeles et al (2007) developed a 3D morphological model that solves an advection-diffusion equation for sand and mud, both sediment classes being transported in suspension. They first fitted the sand resuspension law in order to simulate horizontal sand fluxes in equilibrium conditions. These fluxes correspond to transport capacities from literature, under current alone or current and waves. The law was calibrated for fine sand $(200 \mu \mathrm{m})$. Theses authors also checked that the adjustment length (i.e. the distance of underloading transport of sand) is of the same order of magnitude as measured in a flume by Van Rijn (1985). Like van Ledden (2002), Waeles et al (2007) also considered two regimes, separated by a critical mud fraction in the surficial sediment, $f_{m \text { cr }}$, equal to 0.3 . The critical shear stress for erosion depends on the mud fraction, starting from the Shields critical value for pure sand, slightly increasing up to $f_{m}$, and then linearly varying to pure mud shear strength. One of the most original features of their model is the way they manage deposition: depositing material is either mixed to the surficial sediment or constitutes a new layer, depending on its own mud content and the mud content of the surficial sediment. Three cases are distinguished and the following procedure is implemented:

- sandy or muddy deposit on muddy sediment: if the bed is consolidated (i.e. its concentration exceeds a given threshold chosen for the simulation), the deposited material forms a new layer, whereas if the mud is soft, deposits are mixed to the surficial layer;

- $\quad$ sandy deposit on sandy sediment: mixing, like for deposition on soft mud;

- $\quad$ muddy deposit on sandy sediment : a new layer is generated.

Waeles et al. (2007) did not take consolidation into account, but an empirical formulation for this process was introduced in a new version of the model (Waeles et al., 2008): the relative mud concentration, defined as the mass concentration of fine particles in the space between sand grains, tends towards an equilibrium profile through a relaxation term. The rate of increase itself depends on the relative mud concentration, while the equilibrium profile accounts for the weight of sediment above each layer, including the weight of sand. No active layer is invoked because the 
erosion depends on a unique critical shear stress for both sand and mud and because the erosion rate of each class is proportional to its own mass content in the mixture.

Recently, Sanford (2008) proposed a comprehensive model, still with two sediment classes: the sand and mud fractions are eroded separately, so that no distinction between cohesive and non cohesive regimes is required. Besides, depositing material is always mixed with the upper sediment layer. Sand is transported in suspension (bed load is not taken into account). Sand erosion is computed from Harris and Wiberg (2001) erosion law, whereas the erosion of mud is proportional to the excess shear stress, the critical value increasing with "material" depth (mass of sediment above the current layer, in kg. $\mathrm{m}^{-2}$ ). The sediment column is split into thin layers that follow material coordinates (in kg.m ${ }^{-2}$ ). Within each layer, the erodibility is supposed to vary linearly; this approach represents the continuity of processes more accurately, for instance in areas close to the water/bed interface, especially during consolidation phases. Like in Waeles et al. (2008), consolidation (density and shear strength) is simulated with a first-order relaxation to an equilibrium state, the profile of which is empirically defined, following a negative exponential function of the material coordinate (the way the sand content distribution influences consolidation is not described, and the application presented in the paper does not account for this process). The consolidation rate is also empirically quantified: fitting with observations from consolidation tests leads to a rate of 0.9 day $^{-1}$. Since the equilibrium profile is defined relatively to the instantaneous bed-water interface, it moves down (respectively up) during erosion (respectively deposition). In agreement with this assumption, a slow concentration decrease (softening or swelling) is allowed when the equilibrium value is exceeded, for instance after erosion. Sanford (2008) also accounts for bioturbation processes through the introduction of additional mixing between sediment layers. No explicit expression of a so-called "active layer" is specified. However, the mass $\left(\mathrm{kg} . \mathrm{m}^{-2}\right)$ of the surficial layer is maintained between a minimum and a maximum value, and erosion as well as deposition only affect this layer within a given time step, so that this range of the surficial layer mass characterizes an implicit active layer.

Literature is more abundant concerning the simultaneous transport of several classes of sand. Among others, recent works from Blaas et al (2007) and Warner et al. (2008) can be cited. Blaas et 
al. (2007) use the method proposed by Garcia and Parker (1991) to account for hiding and exposure processes which are weighted by a sorting index (erosion of a mixture is reduced when the bed is less sorted). Warner et al. (2008) consider bed load and transport in suspension, the erosion fluxes being limited by the availability of each sediment class in the top layer. At any time step, the top layer should be at least as thick as the active layer: the underlying layers may therefore feed the upper layer in case of excessive sediment depletion in the surface layer. Like in Harris and Wiberg (1997), the active layer thickness is calculated every time step as a function of the sediment grain size and of the excess shear stress (averaged over all sediment classes): the higher the bottom stress, the thicker the active layer. The introduction of cohesive sediment processes in this modelling framework is under development.

It can be noticed that an active layer concept is required as soon as erosion rates are managed separately for the different sediment classes. In that case, the erosion of any class should be limited to the mass available in the "active" layer. If this restriction is not respected, the erosion of easily resuspended classes would be likely to occur in deep layers, which is physically not realistic.

Neumeier et al. (2008) propose a new version of Sedtrans software based on a multiclass approach for cohesive sediments; they simultaneously account for sand transport as bedload only. Mixed sediments are not dealt with. An empirical consolidation procedure is planned but not operational yet.

The simulation of cohesive sediments requires that a time-variation of erodibility due to consolidation be taken into account. Since Hayter (1986), several techniques for simulating consolidation were proposed. The simplest methods consist in 1) splitting the sediment into layers characterized by their density and/or shear strength and 2) translating the consolidation into a residence time concept (Hayter, 1986; Teisson, 1991) or into a regular mass transfer with the underlying layer which is more consolidated (Le Hir and Karlikow, 1991). Another empirical technique is based upon an increase of sediment density (or shear strength) at each time step for each layer, according to a relaxation law towards an equilibrium vertical density profile (Le Hir et al., 1989; Sanford, 2008). Waeles et al. (2008) adapted such a relaxation model in the case of mixed sediment: they consider that the sand fraction contributes to the weight of sediment 
generating consolidation, but that only the relative mud concentration increases during consolidation. Another family of consolidation closure comes from Kynch theory, considering sedimentation as a vertical mass advection. In this case, the expression of the sedimentation rate as a function of the sediment concentration and composition forms a constitutive relationship (Le Hir et al., 2001a).

But the most comprehensive approach, at least for primary consolidation, comes from soil mechanics (Gibson, 1967). The density increase results from a vertical exchange of pore water, the velocity of which follows Darcy law; in this case the forcing is the pressure gradient associated to the vertical increase of total weight after deduction of effective stress and water weight. Although numerous studies are based on Gibson theory (e.g. Toorman, 1996; de Boer et al., 2007), they rarely apply to mixed sediments (except in Toorman and Berlamont, 1993; Toorman, 1996; Merckelbach, 2000; Merckelbach and Kranenburg, 2004). In addition, the need to fit two constitutive relationships (permeability and effective stress as a function of sediment density) can be considered as a drawback.

This short review on mixed sediments transport modelling leads to the following remarks:

- $\quad$ fine sand and mud are generally transported in suspension; deposition fluxes of different sediment classes are computed according to the respective bottom concentration and settling velocities, whereas erosion fluxes for each class are either proportional to their respective fraction in the surficial sediment (e.g. Chesher and Ockenden 1997; Waeles et al., 2007; van Ledden, 2002 in the cohesive regime) or computed separately (van Ledden, 2002 in the non-cohesive regime; Sanford, 2008), with or without dependence on the sand/mud ratio in the sediment;

- as soon as the erosion flux of any class does not respect the content of this class in surficial sediment , an "active layer" concept is required, in order to account for bed-armouring;

- in operational models, consolidation is generally neglected or dealt with empirically, although Gibson theory, coming from soil mechanics, has been developed for a long time; 
this theory involves two constitutive relationships (and the prescription of corresponding additional parameters), and has been mainly investigated for cohesive sediments;

- present-day models can be distinguished by the way they manage deposition: deposited sediments are either systematically mixed with surficial sediment, or form a new layer when their characteristics are different from the surficial sediment ones (Waeles et al., 2008);

- according to the authors' knowledge, no published modelling strategy considers simultaneously all the above mentioned processes that are related to mixed sediments: most often, the use of simplified algorithms and the discretization hypotheses prevent the comprehensive simulation of these processes; for instance, accounting for the variability of sediment erodibility requires to compute the vertical distribution of each sediment class, and to simulate consolidation processes fitted to mixed sediments.

This paper describes a modelling strategy which offers the possibility to account for most processes discussed above: simultaneous bed load and suspended sediment transport, mixing of several sediment classes in the water column as well as in the sediment, consolidation of muddy and mixed sediments with possible segregation of sand particles by adapting Gibson theory, management of erosion fluxes depending on the cohesive or non-cohesive nature of the surficial sediment. Special attention was paid to the way the sediment layers content is updated after deposition, in order to simulate possible pore filling up between large particles in surficial sediment before creating a new layer.

The novelty of our modelling approach does not lie so much in the process formulations and techniques, but rather in the way sediment layers are managed as well as in the consolidation of mixed sediments. However, it seems important to give an overview of the different sections of the code, in order to understand how the different processes interact, and why they require a detailed representation of the sediment structure. This is done in section 2. Section 2.4 is dedicated to some validation of the mixed sediment consolidation model, whereas section 3 aims to show the impact 
of the sediment modelling strategy on resulting sediment transport, through a simple onedimensional (1DV) application.

\section{Model structure}

The sediment model aims to simulate the transport and evolution of all kinds of sediment mixtures under the effect of hydrodynamic forcing (waves and currents) in coastal environments. It manages the transport in the water column, according to a depth-averaged formulation or to a 3D framework, exchanges with the bed by erosion and deposition, and consolidation processes in the bed. As a result, suspended sediment concentrations and related fluxes are simulated; in addition morphological changes are likely to occur, as well as changes in sediment nature, by mixing or sorting. All these features are successively described hereafter.

In the present version of the model, the bedload module is not yet implemented. Suspended transport is computed by solving an advection-diffusion equation for the concentration of different particle classes.

\subsection{Selection of state variables and sediment facies description}

The sediment description is based on the selection of sediment classes for which the mass concentrations constitute the model state variables. These sediment classes are usually typical grain-sizes, the number of which reflects the model "sedimentological resolution". These classes are grouped into three types defined by their behaviour:

- the "coarse" type is generic for non-cohesive particles that are transported as bedload only: it is normally affected to coarse sand, and can be extended to gravels, cobbles and pebbles;

- the "sand" type is generic for non cohesive particles that are transported in suspension: it refers to fine sand, but also to medium sand, since the possibility to simulate transport 
capacities through an advection-diffusion process has been demonstrated (Waeles et al., 2007);

- the "mud" type is generic for cohesive particles; these are naturally transported in suspension, but are also likely to flocculate (inducing a variation of settling velocity) and to undergo consolidation in the bed; the mud type is usually affected to silt and clay, but could also be used for organic matter.

It should be noted that a same grain size could be classified as "coarse” or "sand", depending on the type of transport the model user wants to favour: for instance, a $500 \mu \mathrm{m}$ sand (medium sand) could be considered as "sand" or "coarse" (same for a silt that could belong either to a sand class or to a mud class). However, in the present version of the model, a given category is transported according to a unique mode: this constitutes a simplifying assumption, and the model could be upgraded from this point of view. Formally, two classes corresponding to two different types could be affected to a same grain size, but the possible sorting that could result would be an artefact to be avoided.

Even in the case bedload transport is not implemented, it is important to account for the presence of particles (“coarse" type) which are not transported in suspension, since they are likely to induce “armouring” processes or to influence the filling of sediment layers (see §2.3).

Sediment facies are constituted by a given combination (in mass) of the sediment classes. For instance a muddy sand can be made of $50 \% 200 \mu \mathrm{m}$ sand (fine sand), $20 \% 500 \mu \mathrm{m}$ sand (medium sand), $25 \%$ silt and $5 \%$ clay (both mud).

A major difficulty for implementing the model is the choice of the state variables, since natural size-spectra are often continuous and the computation cost increases with the number of state variables. On the other hand, once these variables are selected, the characterization of initial sediment facies is straightforward, provided that the surficial sediment map is known.

Managing simultaneously the 3 types of sediment classes lead to an original bed model, which has to account for realistic space filling with particles. Typical ranges of porosity have to be respected whatever the combination of sediment classes. A volume concentration of well sorted sediment 
$\left(C_{v o l}\right.$ sort $)$ is then affected to coarse particles or sands when only one class is present, whereas the concentration can exceed this value when several classes are mixed, up to a new maximum $\left(C_{\text {vol }}\right.$ mix).

Figure 1 shows the running sketch of any time step of the model. First, the erosion fluxes are computed for every state variable, and the surficial sediment composition is updated accordingly. Then deposition tendencies of all classes $i$ are computed as factors to be multiplied by the concentrations $C_{i}$ in the bottom cell of the water column model. The actual deposition fluxes are only known after the following transport step, as these terms which involve the state variables $\mathrm{Ci}$ are implicit in the advection/diffusion equations. Deposition is then managed in the bed, with possible addition of sediment layers. Minimum and maximum thicknesses are assigned to the layers, and constitute numerical parameters of the model. Last, a consolidation step is run, depending on the consolidation option and time step (the latter can be larger than the transport step).

These different steps are briefly described in sections 2.2 to 2.4 .

Figure 1: sketch of a running time step of the model

\subsection{Erosion of sand/mud mixtures}

An original feature of the model is the way the resuspension of sand and mud mixtures is managed. It results from observations with a small flume, the "Ifremer Erodimetre” (Le Hir et al., 2008) and is based on the distinction between cohesive and non cohesive behaviours, as expressed by van Ledden (2002) and Waeles et al. (2008). An erosion law is first selected for each of the homogenous sediments, and the method to derive an erosion law for a sediment mixture is then described. It should be noted that the modelling strategy is normally suitable for any change or upgrade of the sand and mud erosion laws. 


\section{Pure sand erosion law}

Literature concerning sand erosion laws is not very rich, and experimental validation is rarely published. Roberts et al. (1998) present a comprehensive data set of quartz particle erosion tests. They expressed the erosion rate as a function of the excess-shear stress to a power in the range 1.62.2, depending on the sand diameter (higher power for smaller particles). Except for Engelund and Fredsoe erosion law (1976), most of published sand erosion laws, often called pick up functions, are expressed in the form (van Rijn (1984), Beach and Sternberg (1988), Nielsen (1992), in Le Hir et al., 2008):

$$
E_{\text {sand }}=E_{0, \text { sand }}\left(\frac{\tau}{\tau_{e s}}-1\right)^{n s} \quad \text {, if } \tau>\tau_{\text {es }}
$$

where $\tau_{e s}$ is the critical stress for erosion of these particles, according to Shields diagram. $n s$ is generally close to 1.5 . Interestingly, Smith and McLean (1977) propose a modulation of the “constant" $E_{0}$ as a function of $\tau$, in order to limit the erosion flux when $\tau$ becomes very large:

$$
E_{\text {sand }}=E_{0, \text { sand }}^{\prime} \gamma \frac{\left(\frac{\tau}{\tau_{e s}}-1\right)}{1+\gamma\left(\frac{\tau}{\tau_{e s}}-1\right)}
$$

Recently, Dufois (2008) calibrated the constant $E_{0}$ sand of equation (1) by simulating equilibrium transport rates with a 1DV (one dimensional vertical) model, and by fitting parameters to get a transport capacity in the range of published formulae. He found a strong increase of the fitted $E_{0}$ sand with sand diameter.

In the present state of our model, for a pure sand mixture, equation (1) is applied with $E_{0}$ sand (resp. $\tau_{e s}$ ) averaged over the erosion parameters of the different sand classes, weighted by their respective mass concentration. Alternatively, hindering or exposition parameters could be introduced in the erosion law in order to account for interaction between sand classes (e.g. Wu et al., 2000). 


\section{Mud erosion law}

For pure mud, the Partheniades-Ariathurai erosion law is prescribed:

$$
E_{\text {mиd }}=E_{0, \text { mud }}\left(\frac{\tau}{\tau_{\text {em }}}-1\right)^{n m} \quad \text { if } \tau>\tau_{\text {em }}
$$

As most often in literature, $\mathrm{nm}$ is chosen equal to 1 , while the critical shear stress for erosion $\tau_{e m}$ and $E_{0 \text { mud }}$ remain parameters to be fitted from erosion tests. Both $\tau_{e m}$ and $E_{0}$ mud are likely to change according to the variations of mud mass concentration that result from consolidation processes (see section 2.4). In the present state of the model, $E_{0}$ mиd is constant, and only $\tau_{\mathrm{em}}$ depends on consolidation.

\section{Erosion of sand/mud mixtures}

The erosion behaviour of a mixture of sand and mud is deduced from the literature and recent experimental works (Le Hir et al., 2008). Different cases are considered, depending on the mud fraction (dry mass of mud divided by total dry mass). Confirming previous results from Panagiotopoulos et al. (1997), erosion tests in a small flume showed that below a critical mud fraction, the mixture behaves like pure sand, whereas above this critical value the shear strength increases with the mud fraction (fig.2). The increase rate is likely to vary with the relative mud concentration. In addition, the critical mud fraction seems to increase with the sand mean diameter: this is interpreted as a need for more fine particles to fill the voids between sand grains, when they are large, before getting a higher strength matrix (Le Hir et al., 2008). On the other hand, once a mud matrix begins to form in the presence of large sand grains, the strength seems to less depend on the mud fraction, which may be because the matrix cannot strengthen as much (fig.2). This seems in agreement with and complements the conceptual framework for erosion behaviour of 
sand-mud mixtures proposed by van Ledden et al. (2004b). They showed a more gradual transition from non-cohesive to cohesive behaviour when the network structure is silt-dominated, and a sharp transition when the structure is sand-dominated. In our observations, analogous distinctions can be made between fine sands and medium sands. For van Ledden et al. (2004b) the cohesion is better described by the clay content than by the mud content, which was not the case in our observations, may be because the range of clay/silt ratio was too small. Recently, Jacobs et al. (2010) investigated the erodibility and the rheological behaviour of artificial sand-mud mixtures. They showed a positive relationship between the critical shear stress for erosion and the indirect plasticity index, deduced from the product of the activity of the soil, characteristic of its mineralogy, by the clay mass fraction. But for low cohesive soils, $\tau_{e}$ also appeared to increase with the silt content. Although more investigation is required on the subject, we can suggest that the conceptual framework for erosion behaviour proposed by van Ledden et al. (2004b), based on the textural classification provided by ternary diagrams (sand/silt/clay ratios), be extended by additional distinctions between sand grain sizes.

Figure 2: Critical shear stress for erosion of sand/mud mixtures as a function of the mud fraction and the sand diameter. The two dotted lines show different shear strength variations with mud fraction, depending on the sand diameter. [Adapted from erodimetre tests in Le Hir et al. (2008), carried on natural mud from the bay of Brest, characterized by muscovite, illite and montmorillonite as dominant clay minerals, and a large organic content (5.4\%)].

It is then proposed to formulate the critical shear stress for erosion of mixed sediments as described on figure 3. The critical mud fraction mud fr1, below which the Shields threshold is applied together with the erosion flux (1), linearly increases with the mean sand diameter. In agreement with Panagiotopoulos et al. precursor work (1997) this mud fraction ranges from 20 to $40 \%$ for fine sand, and finally, its variation is as following:

$$
\text { mud fr } 1=\alpha_{0} D
$$

where $D(m)$ is the mean diameter of sand fractions and $\alpha_{0}$ is set in the range $1-3.10^{3} \mathrm{~m}^{-1}$. 
A second critical mud fraction mud fr2 is chosen (typically $70 \%$ ), beyond which the mixture behaviour is fully cohesive. Beyond mud fr2, the mixture shear strength depends on the relative mud concentration, as stated by Migniot (1989) and Waeles et al. (2008). This relative mud concentration is defined as the mass of mud in the space between sand (and gravel) grains and can be expressed as:

$$
C_{\text {relmud }}=\frac{C_{\text {mud }}}{\left(1-\varphi_{s}\right)}
$$

where $C_{\text {mud }}$ is the mud mass concentration and $\varphi_{s}$ is the sand (and gravel) volumetric concentration.

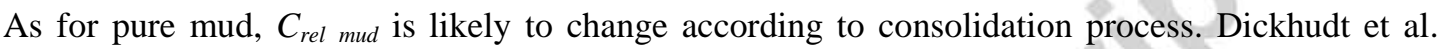
(2010) recently showed from published data sets that the sand/mud mixtures erodibility was correlated to the volumetric concentration of mud in the (mud+water) matrix, which is $C_{r e l ~ m u d} / \rho_{s}$ when the solid particle density $\rho_{s}$ can be assumed similar for sand and mud. In the present state of the model, a classical power law is adopted for the mud shear strength (either pure or sandy):

$$
\tau_{\text {em }}=\alpha_{1} C_{\text {relmud }}^{\alpha_{2}}
$$

where $\alpha_{1}$ and $\alpha_{2}$ are calibrated from erosion tests.

The erosion flux (2) then applies. When the mud fraction is between mud fr1 and mud fr2, the erosion parameters ( $\tau_{e}, n m$ and $E_{0}$ ) are linearly interpolated from the respective sand and mud parameters, according to the mud fraction.

Figure 3: Conceptual relationship between the critical shear stress for erosion of sand/mud mixtures and the mud fraction, depending on the mean size of sand particles and the relative concentration of mud. 
The mud fraction therefore determines the sediment behaviour and the erosion law to be applied, however the erosion flux of any class of sandy or muddy types is always proportional to the mass fraction of this class in the surficial sediment.

\section{Managing sediment layers during erosion}

The surficial sediment erosion only affects sand and mud types. Coarse classes may subsist and then could prevent the erosion of sediment layers below. This is not realistic when the equivalent thickness of gravels is small, for instance after erosion of sand and mud fractions, when the thickness of the upper layer has been updated in order to respect the volumetric concentration $C_{\text {vol }}$ sort The concept of active layer is then used to allow further erosion down to the base of the active layer. During one time step $d t$, the surficial sediment is first eroded at the rate given by the erosion flux, during $d t 1$; if $d t 1<d t$, erosion of the underlying sediment then starts, and lasts until the time step is over or the active layer is fully investigated (whichever comes first).

\subsection{Managing sediment deposition}

The general formulation for the sediment deposition flux follows Krone law:

$$
D_{i}=W_{s i} C_{i}\left(1-\frac{\tau}{\tau_{d i}}\right)
$$

where $W_{s}$ is the settling velocity and $C$ is the suspended sediment concentration, but where the critical shear stress for deposition $\tau_{d i}$ only reflects a possible lack of explicit consolidation in the bed model: if consolidation is not accounted for, $\tau_{d i}$ ranges from 0.1 to $0.5 \mathrm{~N} . \mathrm{m}^{-2}$ in order to prevent deposition when turbulence is high enough to generate immediate resuspension of freshly deposited material. On the other hand, $\tau_{d}$ is chosen infinite [i.e. $\left.D_{i}=W_{s i} C_{i}\right]$ when consolidation is simulated, since in that case unconsolidated deposited material can easily be eroded. Intermediate cases are possible: when the minimum mud density of deposits, which is a model parameter, is selected large enough to avoid short consolidation time steps (cf. § 2.4), it is necessary to limit 
deposition when turbulence intensity (parameterised by $\tau$ ) is high. This conceptualisation of the deposition term is in agreement with Winterwerp (2007) who stated that the so-called critical shear stress for deposition actually "represents a critical shear stress for erosion of freshly deposited sediment”, as also interpreted by Krone himself.

The settling velocity $W_{s i}$ is not discussed in this paper. In the present version of the model, Soulsby' formulation (1997) is considered for sands, whereas for mud, flocculation processes are taken into account through an empirical relationship between $W_{s}$ and the suspended concentration C (Le Hir et al., 2001b), multiplied by a function of turbulence, as expressed by van Leussen (1994).

An extrapolation procedure is run to account for possible large differences between the concentration in the bottom cell of the water column model, which can be depth-integrated, and the near bed concentration, where deposition takes place. A Rouse equilibrium profile is assumed within the bottom cell, with a specific Rouse number for each state variable, since it depends on the settling velocity. The near-bed concentration is computed at a reference level $h_{\text {ref }}$. The extrapolation is "conservative”, in a sense that the integral of the Rouse-like concentration profile from $h_{\text {ref }}$ up to the top of the bottom cell equals the product of the mean concentration computed for the bottom cell by the height of this cell (Waeles et al., 2007). The reference level has to be compatible with the sand erosion rate: because of the strong dependence of the settling rate on $h_{\text {ref }}$, and because at equilibrium, the deposition rate balances the erosion rate, the latter should be fitted to the same reference level. Typically, $h_{\text {ref }}$ is selected at a height equivalent to the Nikuradse roughness length (2 to 3 times $D_{50}$ ), however, it is sometimes set a few centimetres above the bottom, depending on the deposition formulation which was considered along with the erosion law. This ambiguity on the reference level is troublesome, rarely discussed in literature, and requires more attention.

This special attention regarding the near bed sand distribution is achieved without accounting for the possible changes in turbulent mixing induced by high concentrations (e.g. Le Hir et al, 2001b). Such features typically occur in near bottom fluid mud layers, and can be managed with a proper turbulence closure in the water column. Recent works have been published on this subject; 
however, despite their high importance, these features are considered out of the scope of the present paper, just like the flocculation processes are.

After the transport equation has been solved, the actual deposition on the bottom is computed. The new deposits density is required. Two volume concentrations for non cohesive sediments are considered: one ( $\left.C_{\text {vol sort }}\right)$ for well sorted sediments, the other one $\left(C_{\text {vol mix }}\right)$, larger, for mixtures of gravel and sand classes. The general procedure is represented on fig. 4a and $4 \mathrm{~b}$. It consists in first depositing coarse particles with a given volume concentration, then sands and, finally mud. When a sediment layer is constituted by only coarse particles, its concentration is $C_{\text {vol sort }}$ : any added sand will first fill up the pores between the grains until $C_{\text {vol mix }}$ is reached, then the remaining sand will be deposited with the concentration $C_{\text {vol sort }}$, from which an increase of layer thickness can be deduced. If mud also settles, it will fill up pores between gravels and sands, until one of the following criteria is satisfied: either the total concentration $C_{\text {vol mix }}$ is reached, or the relative concentration is $C_{\text {relmud ini }}$, is reached. The latter value represents the initial concentration of muddy deposits, before consolidation starts. If there is more to be deposited than the space available in the porous medium, the excess mud will be added to the mixture with the concentration $C_{\text {relmud ini, }}$ from which the new layer thickness can be computed. The relative mud concentration is likely to increase according to consolidation processes $(\S 2.4)$. $C_{\text {relmud ini }}$ is typically in the range $50-150 \mathrm{~kg} \cdot \mathrm{m}^{-3}$, in the hindered settling domain and below the so-called "gel concentration” (e.g. Winterwerp and van Kesteren, 2007), but a higher value can be chosen in order to save computing time for consolidation.

In order to not mix fresh deposits and partially consolidated sediments, the surficial layer is completed by new deposits only if its relative concentration is lower than a critical value $C_{\text {relmud }}$ r which constitutes another parameter of the model. Last, the upper layer thickness $d z s$ should remain in a given range [dzsmin : dzsmax]. All these features make the procedure complex. The main reason for that is the short duration of a time step (related to the hydrodynamic time scale), typically of the order of one minute, which results in a small quantity of deposited sediment during each time step. A compromise has to be sought between a systematic mixing in the upper layer and the wish to respect the particulate content that will control the sediment behaviour. Figure 4 synthesizes the algorithm. 
Figure 4a: sketch of the deposition procedure

Figure 4b: representation of the layer filling, showing the successive steps from left to right.

Case a: coarse material, sand and mud classes are present (a1: adding sand in the layer induces a concentration increase below $C_{\text {vol mix }}$; a2: the amount of added sand is too large to satisfy $C<C_{\text {vol mix }}$ without an increase of the layer thickness) [other sub-cases are possible].

Case b: no coarse material (sub-cases are possible)

Case c: no coarse material, no sand

\subsection{Consolidation of sand / mud mixtures}

The bed model is run for two purposes: (i) the bed content is likely to vary in three dimensions, according to successive erosion and deposition events, (ii) the surficial sediment erodibility, which controls erosion fluxes, depends on the consolidation state of the bed. In the case of mixed sediment dynamics, the consolidation process should account for mixtures of sand and mud. However, literature is rather poor on this subject, since most consolidation studies apply to pure mud. While Toorman (1996) builds up a unifying theory for sedimentation and consolidation of several classes of sediment, Merckelbach (2000) writes two vertical mass conservation equations for sand and mud, which differ during the hindered settling phase. Following Merckelbach's derivation of Gibson equation, and using as state variable the mass concentration of each sediment class $C_{i}$, the mass conservation equation during consolidation can be written as:

$$
\begin{aligned}
& \frac{\partial C_{i}}{\partial t}=\frac{\partial}{\partial z}\left[\frac{k}{\rho_{w}} C_{i} \Delta(\text { load })\right] \\
& \text { with } \Delta(\text { load })=\left(C \frac{\rho_{s}-\rho_{w}}{\rho_{s}}+\frac{1}{g} \frac{\partial \sigma^{\prime}}{\partial z}\right)
\end{aligned}
$$


where $C$ is the sediment total mass concentration, assuming the same grain density $\rho_{\mathrm{s}}$ for all classes, $k$ is the permeability $\left(\mathrm{m} \cdot \mathrm{s}^{-1}\right), \rho_{w}$ is the water density, $g$ the gravity and $\sigma^{\prime}$ the effective stress.

Dealing with sand and mud mixtures, differential settling is likely to occur. In order to account for segregation due to polydispersity during sedimentation, Toorman (1996) suggests to add a diffusive flux in the mass conservation equation. An alternative method is used here: when the sediment density is low, the settling velocity is chosen as the maximum between the sedimentation rate in (4) and the hindered settling velocity $W_{\text {si,hindered }}$ of the class considered, so that finally equation (5) is solved:

$$
\frac{\partial C_{i}}{\partial t}=\frac{\partial}{\partial z}\left[C_{i} \max \left(\frac{k}{\rho_{w}} \Delta(\text { load }), W_{s_{i, \text { hindered }}}\right)\right]
$$

Recently, de Boer et al. (2007) proposed an elegant simplified method to solve Gibson equation by means of a Fourier series. Unfortunately this approach seems difficult to apply in cases where "initial” conditions are likely to change at any time step, as it happens when erosion or deposition occur. It can be noted that de Boer et al. (2007) use material vertical coordinates (as Gibson did). Alternatively, Sanchez (1992) suggests solving Gibson equation with iso-concentration coordinates, and Thiébot et al. (2008) propose a multi-layer model, each layer being characterized by a given concentration and a thickness deduced from Gibson theory. The latter formulation does not seem adapted to mixed sediments, where the range of concentration strongly depends on the sand content.

Although the use of material coordinates could simplify the computations, Eulerian vertical coordinates were chosen in this model, the algorithm having already been implemented in a preexisting bed model (Le Hir et al., 2001a). 
The resolution of equations (5) requires the specification of two constitutive relationships (e.g. Toorman, 1999). The model can be used with several closures, but presently, the following relationships are coded:

- the permeability $k$ is a function of the void ratio $e$ and a representative grain diameter chosen as $D_{20}$, in order to account for the limitation of pore water flow preferentially induced by smaller particles (Koenders and Den Adel, in Soulsby, 1997):

$$
k=k_{1} D_{20}^{2} e^{k_{2}}
$$

$e$ is deduced from the concentration $C$ with: $e=\rho_{s} / C-1$

for low concentrations, the permeability $k$ cannot exceed $(1+e) \cdot W s_{D 20} /\left(\rho_{s}-\rho_{w}\right)$, where $W s_{D 20}$ is the settling velocity of individual grains $D_{20}$.

- the effective stress is computed from the relative concentration of mud through an empirical power law:

$$
\sigma^{\prime}=\sigma_{1} C_{\text {relmud }}^{\sigma_{2}}
$$

The assumption that sand grains do not contribute to effective stress seems reasonable only when the sand volume fraction is low, and probably not when it increases. In this case (7) should be reconsidered. This expression of effective stress is actually close to the formulation deduced by Merckelbach and Kranenburg (2004), who applied the fractal theory (scale invariance of the clay network) and found:

$$
\sigma^{\prime}=\sigma_{3}\left[\frac{\varphi_{\text {clay }}}{1-\varphi_{s}}\right]^{\sigma_{4}}
$$

where $\sigma_{4}=2 /(3-f)$, with $f$ the fractal dimension. In fact, $C_{\text {rel mud }}=\rho_{s} \varphi_{\text {mud }} /\left(1-\varphi_{s}\right)$, and generally, for a given sediment, the ratio $\varphi_{\text {clay }} / \varphi_{\text {mud }}$ remains constant. Under these conditions, the expressions (7) and (8) are equivalent.

$k_{1}, k_{2}, \sigma_{1}, \sigma_{2}$ (or $\sigma_{3}$ and $f$ ) are parameters to be calibrated, normally by means of settling column tests. Practically, $\sigma_{1}$ and $\sigma_{2}$ are computed from vertical profile of sediment concentration at the end 
of the primary consolidation phase, when excess pore-water pressures are dissipated. $k_{1}$ and $k_{2}$ are then evaluated in order to simulate the rate of sediment height decay.

Additional features were introduced for sand-mud mixtures:

- (i) if the concentration of any sandy or gravel class reaches the maximum concentration of a well-sorted sediment $\left(C_{\text {volsort }}\right)$, or if the overall concentration of the sediment exceeds the maximum concentration of a mixed sediment $\left(C_{\text {volmix }}\right)$, the consolidation process is stopped;

- (ii) the load (in equation 5) cannot be negative: it is set to zero, for instance when the effective stress is likely to exceed the actual immersed weight after erosion; as a consequence, the load increase with depth in the sediment has to be checked: if this condition is not met, the load gradient in (5) is set to zero;

- $\quad$ (iii) for low concentrations, permeability $k$ cannot exceed the limit $k_{\max }$ with

$$
k_{\max }=(1+e) W_{s} \rho_{w} /\left(\rho_{s}-\rho_{w}\right)
$$

where Ws is the non-hindered settling velocity of grains whose diameter $D_{20}$ was chosen as representative for permeability; this expression relates the permeability to the settling rate when no effective stress takes place (e.g. Been, 1980 in Toorman, 1996);

- (iv) the hindered settling is formulated semi-empirically as:

$$
W s_{i, \text { hindered }}=W s\left[1-0.0008 \sum_{i} C_{i, \text { sand }}-0.003 \sum_{j} C_{j, \text { mud }}\right]^{4.65}
$$

where the power 4.65 results from Richardson and Zaki (1954) observations, and where $0.0008 \Sigma_{\mathrm{i}}\left(C_{i, \text { sand }}\right)+0.003 \Sigma_{\mathrm{j}}\left(C_{j, \text { mud }}\right)$ represents an “effective” volumetric concentration of sand and mud;

- (v) after a consolidation step, the total concentration of the surface layer is maintained and mass conservation is preserved by reducing its thickness; 
- (vi) when the total concentration of any layer is below a minimum value (typically 30 kg. $\mathrm{m}^{-3}$ ) or when its thickness is too small (typically $<0.01$ to $0.1 \mathrm{~mm}$ ), this layer is merged with the underlying layer which keeps its former concentration and increases in thickness.

Figure 5 shows results of settling tests simulation for Marennes-Oléron Bay natural mud (France). The agreement is fairly good, except for the test with a low initial concentration, which shows a too rapid consolidation. The calibrated set of parameters is $k_{1}=0.2, k_{2}=5, \sigma_{1}=1.510^{-14}, \sigma_{2}=6$.

Figure 5: simulation of consolidation tests with natural mud from Marennes-Oléron Bay (France). Successive positions of the water/sediment interface are shown, for 3 initial concentrations. Measurements contain replicates (curves), and simulations are represented by circles.

The model capacity to simulate segregation has been validated by simulating a settling test experiment published by Merckelbach and Kranenburg (2004). The initial slurry is a natural mud from the Dollard estuary (NL), constituted of $43 \%$ clay, $41 \%$ silt and $16 \%$ sand. The sand diameter is estimated $\sim 80 \mu \mathrm{m}$ and the initial density is $1070 \mathrm{~kg} \cdot \mathrm{m}^{-3}$. Results are presented in figure 6, with constitutive relationships fitted to this experiment (here, the permeability is computed as $k=k_{1} C_{\text {relmud }} k_{2}$ ). The agreement between measurements and computations is noteworthy: in particular, the water/sediment interface is well located, and the observed stratification close to the bed is reproduced. The simulation reveals that this stratification occurs rapidly, due to partial segregation of sand, as allowed by equation (5).

Figure 6: simulation of consolidation test with natural mud from the Dollard estuary (The Netherlands). Successive density profiles simulated (left panel) or measured (right panel) 11, 29, 39 and 63 days after 
initial mixing. The sand fraction is $16 \%$, with an estimated sand diameter of $80 \mu$. The initial density is 1070 $\mathrm{kg} \cdot \mathrm{m}^{-3}$, the initial height $1.60 \mathrm{~m}$ (only the lower $60 \mathrm{~cm}$ are represented). Fitted constitutive relationships are $\mathrm{k}$ $=2.10^{13} C_{\text {relmud }}^{-8}$ and $\sigma^{\prime}=10^{-21} C_{\text {relmud }}^{9}$ for permeability and effective stress respectively. Data from Merckelbach and Kranenburg (2004).

\section{Application of the sediment model}

In order to illustrate the benefits of this new modelling strategy, this section points out some original features related to the sediment management, obtained from various application cases.

\subsection{Consolidation tests}

Figure 7 shows settling column tests simulation results, and exhibits several particular features of the consolidation algorithm that will be commented on. Successive concentration profiles are shown, starting from an initial vertically uniform distribution. The constitutive relationships parameters correspond to mud from Marennes-Oléron Bay.

Figure $7 \mathrm{a}$ shows the effect of the initial concentration on the mud consolidation velocity. Classically, two interfaces quickly appear, between clear water and the initial suspension near the surface, and between this suspension and a developing denser sediment layer close to the bottom. The dispersion of the second interface is due to variations of the sedimentation rate when the concentration increases. A third interface may even appear (Fig. 7a right) when the initial concentration is low. The final concentration profile in the upper layers is independent of the initial concentration: at this stage of the consolidation process, the excess pore-water pressure is likely to be dissipated and equilibrium is reached, so that the vertical load gradient in equation (4) is zero. The vertical gradient of effective stress can then be computed:

$$
\frac{\partial \sigma^{\prime}}{\partial z}=-g C \frac{\rho_{s}-\rho_{w}}{\rho_{s}}
$$


When only mud is considered, combining equations (7) and (9) leads to a unique vertical profile of concentration and effective stress, which depends on the constitutive relationship. However, this result does not apply in all circumstances (for instance in case the upper sediment has been eroded). This justifies the additional feature quoted (ii) in 2.4, which prevents further consolidation when the vertical load gradient vanishes.

According to relationship (6) between permeability k and particle size $D_{20}$, the consolidation rate is likely to be reduced when particles are smaller, for instance when the clay to silt ratio increases. This is clear on figure $7 \mathrm{~b}$. In this case too, the final stage of sediment concentration profile is identical for all clay to silt ratios, because the relationship $\sigma^{\prime}\left(C_{r e l m u d}\right)$ does not distinguish the clay and silt contents in the mud concentration. This result deserves future validation experiments.

Lastly, figure 7c represents the consolidation of sand and mud mixture, in the case of a fairly low initial concentration $\left(120 \mathrm{~kg} \cdot \mathrm{m}^{-3}\right)$. The sand fraction rapidly settles through the mud and forms a bottom layer with a density typical of a sandy layer. Such segregation is frequently observed when the concentration of the mixture is low: this can be simulated by solving equation (5). For higher initial concentrations (not shown here), segregation does not occur but the mixture sedimentation rate increases. Similar features (segregation and/or settling acceleration in sand/mud sedimentation) were modelled by Toorman and Berlamont (1993). 
Figure 7 : numerical experiments of consolidation for various initial concentrations or sediment mixture compositions. a) Test with mud only, and two initial concentrations (150 kg.m $\mathrm{m}^{-3}$ on the left, $50 \mathrm{~kg} \cdot \mathrm{m}^{-3}$ on the right). b) Test with mud only, initial concentration $=100 \mathrm{~kg} \cdot \mathrm{m}^{-3}$, clay $/ \mathrm{silt}$ ratio $=0.11$ and 9 on the left and right panels, respectively. c) Test with 17\% sand, 75\% silt and 8\% clay fractions, initial concentration: 120 kg.m $\mathrm{m}^{-3}$. 


\subsection{Tidal flow induced resuspension of a mixed sediment}

The second application is related to changes in surficial sediment under the effect of a tidal flow. A vertical one-dimensional (1DV) version of the model is used in this case, and the tidal forcing is simply represented by a 12 hour-period sinusoidal variation of velocity or bottom shear stress. The amplitude is modulated over a 14 day-period in order to simulate the fortnightly cycle. The initial sediment is $30 \mathrm{~cm}$ thick and homogeneous. Its mud content is $70 \%$ and its relative mud concentration is $544 \mathrm{~kg} \cdot \mathrm{m}^{-3}$, which corresponds to partially consolidated mud. A 10 hour long storm starting 18 days after the beginning of the simulation (during a spring tide) is simulated through a sudden increase of the bottom stress up to $3 \mathrm{~Pa}$. Such forcing is qualitatively similar to Sanford's 1DV experiment (2008, so that some comparison can be done. Although attention is focussed on the sediment content, the suspended concentration is also shown for a better understanding of sediment dynamics. In this $1 \mathrm{DV}$ approach, the suspended concentration results from mass conservation in a unique $5 \mathrm{~m}$ high cell in the water column, with no horizontal advection. Results are shown figure 8 for the first 24 hours and figures 9 and 10 for the whole 24 day-simulation. Three cases are considered: the reference simulation, as described above, a case "b" without consolidation, and a case "c" without sand. Main parameters are shown in table 1 for the reference simulation. For the sake of simplicity, parameters for both sand and mud erosion laws are chosen identical. This choice also illustrates the specificity of sediment mixtures: differences in sand and mud behaviours mainly arise from distinct settling rates and critical stresses for erosion, and from segregation processes that may occur during consolidation. Nevertheless, erosion parameters and the magnitude of the hydrodynamic forcing were selected in a realistic range in order to compute also realistic suspended sediment concentrations (the current-induced shear stress reaches 1.8 Pa on spring tide, which is representative of macro-tidal estuaries). Last, the vertical resolution of the sediment model is voluntarily fairly coarse $(\sim 1 \mathrm{~mm})$, so as to test the model on a discretization compatible with fully 3D computations. 


\begin{tabular}{|c|c|c|c|c|c|}
\hline Parameter name & value & unit & Parameter name & value & unit \\
\hline skin roughness length & 0.0001 & $\mathrm{~m}$ & initial sediment height & 0.3 & $\mathrm{~m}$ \\
\hline sand diameter & 80 & $\mu \mathrm{m}$ & initial number of sediment layers & 300 & \\
\hline mud representative diameter & 20 & $\mu \mathrm{m}$ & max. layer thickness & 1. & $\mathrm{~mm}$ \\
\hline critic. shear stress mud deposit. & 10 & $\mathrm{~Pa}$ & initial sand conc (uniform) & 214 & $\mathrm{~kg} / \mathrm{m}^{3}$ \\
\hline mud settling velocity & 0.5 & $\mathrm{~mm} / \mathrm{s}$ & initial mud conc. (uniform) & 500 & $\mathrm{~kg} / \mathrm{m}^{3}$ \\
\hline reference height $h_{r e f}$ & 0.05 & $\mathrm{~m}$ & fresh deposit conc. $C_{\text {relmud ini }}$ & 100 & $\mathrm{~kg} / \mathrm{m}^{3}$ \\
\hline$\alpha_{0}$ in mudfr 1 & 3000 & $\mathrm{~m}^{-1}$ & volume conc. $C_{v o l}$ sort & 0.58 & - \\
\hline$n s$ in sand erosion law (1) & 1 & - & volume conc. $C_{v o l ~ m i x}$ & 0.67 & - \\
\hline$E_{\text {Osand }}$ in sand erosion law (1) & 0.0002 & $\mathrm{~kg} / \mathrm{m}^{2} / \mathrm{s}$ & max conc. for mixing $C_{\text {relmud cr }}$ & 200 & $\mathrm{~kg} / \mathrm{m}^{3}$ \\
\hline$n m$ in mud erosion law (2) & 1 & - & min. layer thickness & 0.01 & $\mathrm{~mm}$ \\
\hline$E_{\text {Omud }}$ in mud erosion law (2) & 0.0002 & $\mathrm{~kg} / \mathrm{m}^{2} / \mathrm{s}$ & $k_{1}$ in permeability eq.(6) & 0.2 & \\
\hline$\alpha_{1}$ in $\tau_{\mathrm{em}}$ (mud erodibility) & $2.10^{-9}$ & & $k_{2}$ in permeability eq.(6) & 5 & \\
\hline$\alpha_{2}$ in $\tau_{e m}$ (mud erodibility) & 2 & & $\sigma_{1}$ in effective stress eq.(7) & $1.510^{-14}$ & \\
\hline mudfr2 & 0.7 & - & $\sigma_{2}$ in effective stress eq.(7) & 6 & \\
\hline water height & 5 & $\mathrm{~m}$ & & & \\
\hline
\end{tabular}

Table 1: list of parameters used for the 1DV simulation of the reference case

Figure 8 shows erosion and deposition processes during the tidal cycle. Erosion occurs during the first flow, and the surficial mud content quickly decays. Since the initial sediment is cohesive, this is rather due to sand settling than to sorting processes during erosion. This thin sandier layer is preserved while a fluid sand/mud layer deposits above it during the first slack period. Deposits are sandier at the beginning of the deposition period, and purely muddy at the end (water slack), then 
on top of deposits. This sorting process is related to settling velocity differences between sand and mud, and would occur faster if sand particles were larger.

The mixture consolidation after deposition during slack periods is clearly displayed (Fig. 8a): within 6 hours, the concentration at the base of freshly deposited mud increases from $100 \mathrm{~kg} . \mathrm{m}^{-3}$ (this initial concentration of new deposits is a model parameter) up to about $300 \mathrm{~kg} \cdot \mathrm{m}^{-3}$. This consolidation induces a reduction of mud thickness, but the decay above the sandy layer also results from erosion by the tidal flow after the slack period. Once the fresh deposits are eroded, the underlying mixed layers begin to be resuspended, as the tidal range increases.

The system's behaviour at longer time scales is slightly different (Fig. 9). When the tidal range decreases, deposition dominates, and a thin layer of muddy sand is created (Fig.9d). Neap tide deposits are then constituted of soft mud only that progressively consolidates, up to a concentration of $\sim 350 \mathrm{~kg} . \mathrm{m}^{-3}$. This concentration seems not to change after hour 250 , probably because the total weight of this deposit is low (less than $1 \mathrm{~cm}$ thick). During the following spring tide (from hour 300 to hour 440), the previously reworked sediment is rapidly re-suspended, but the underlying sediment mixture is little eroded, as confirmed by the suspended sediment concentration [SSC] (Fig.9b): the sandy layer seems to "protect" the underlying sediment, because a large fraction of eroded sand continuously settles and has to be eroded again before any erosion of the underlying sediment layers may occur. However, during the storm event (hour 440-450), the bed shear stress is large enough to get the sandy layer fully eroded and maintained in suspension: the underlying sediment can then be easily eroded, and SSC reaches $1.7 \mathrm{~g} / \mathrm{l}$. After the storm, the suspended sediment settles, first slowly because of tidal-induced turbulence, and then rapidly during neap tide. A pure sand layer is first formed (about $1 \mathrm{~mm}$ thick), overtopped by layers of increasing mud content. Consolidation within the overlying soft mud is visible around hour 550: this sedimentation is faster than during the previous neap tide, because of a larger sediment load. Just below this consolidating mud layer (concentration 350- $400 \mathrm{~kg} \cdot \mathrm{m}^{-3}$ at hour 550 on Fig.9c), the mud concentration does not increase: this level is actually sandy (Fig.9d), and consolidation stops once the volume concentration has reached its maximum value. Also, for a given mud concentration, the 
relative mud concentration increases with sand content, so that consolidation significantly slows down with increasing sand content.

Below the sandy layer, the initial mixed sediment undergoes slow consolidation: this feature is not visible on figure 9 because the concentration increase mainly occurs near the sediment bottom, which is not represented here (this will be shown on figure 10). As a consequence, the sandy layer gently settles (by about 1 centimetre within 20 days).

Figure 8: time evolution of surficial sediment (the upper centimetres) during the first two tidal cycles: mud concentration (left panel) and mud fraction (right panel). The white curve represents the flow velocity (either ebb or flood), while the black curve represents the suspended sediment concentration (mud+sand).

Figure 9: Simulation of sediment resuspension and deposition under tidal forcing. Time evolution of sediment characteristics in the sediment and in the water column during 23 days, for the reference case. A storm is simulated after 18 days (imposed bottom stress: $3 \mathrm{~Pa}$ ).

a) tidal flow (forcing); b) depth-averaged suspended sediment concentration (mud + sand); c) sediment height and mud concentration profile in upper centimetres; d) sediment height and mud fraction profile in upper centimetres.

These results are qualitatively consistent with Sanford's (2008; fig.6) ones. Under tidal-induced resuspension of a vertically uniform mixed bed, a thin layer of sand forms quickly, and prevents the erosion of underlying sediment, which impairs any SSC increase. Sanford (2008) evokes a kind of bed armouring by sand reworking. 
In order to assess the impact of consolidation processes and sand content on mud resuspension, two other test-cases were simulated. Test case 2 (Figures 10a, 10b and 10c) consists in neglecting consolidation processes. It is identical to the reference case, except for the call to the consolidation routine which is deleted, and the concentration of mud fresh deposits $\mathrm{C}_{\text {relmud ini }}$ which is set to 490 $\mathrm{kg} \cdot \mathrm{m}^{-3}$, very close to the initial mud concentration $\left(500 \mathrm{~kg} \cdot \mathrm{m}^{-3}\right)$. In addition, the critical shear stress for deposition is changed from $10 \mathrm{~Pa}$ in the reference case (i.e. no turbulence-induced deposition hindering) to $1 \mathrm{~Pa}$. This way, sediment deposition is prevented when the water column is turbulent, which is a common strategy when modelling cohesive sediment transport without consolidation. Under these conditions, implicit consolidation is somehow accounted for, even if no specific sediment evolution is computed. Test case 3 (Figures 10a, 10d and 10e) is similar to the reference case, except for the use of a purely muddy sediment. In that case, the mud concentration is set to $544 \mathrm{~kg} \cdot \mathrm{m}^{-3}$, in order to have the same initial relative mud concentration as in the reference case, and consequently the same erodibility.

Figure 10: Simulation of sediment resuspension and deposition under tidal forcing. Time evolution of sediment characteristics in the sediment and in the water column during 23 days, for test-cases 2 and 3 . A storm is simulated after 18 days (imposed bottom stress $3 \mathrm{~Pa}$ ).

a) tidal flow (forcing); b) depth-averaged suspended sediment concentration (mud + sand) for test case 2 (no consolidation); c) sediment height and mud fraction profile in upper centimetres, for test case 2 (no consolidation); d) depth-averaged suspended sediment concentration (mud + sand) for test case 3 (mud only); e) sediment height and mud concentration profile of the whole sediment column, for test case 3 (mud only). Beware of changes in scales.

In test case 2, without explicit consolidation, the range of erosion and SSC remains the same as in the reference case. Larger differences occur during neap tide, when no suspension is simulated because of the over-estimated shear strength of the fresh deposits. This illustrates the necessity of accounting for consolidation in order to compute accurate SSC magnitudes for all forcing 
intensities. On the other hand, this test-case shows that the amount of residual erosion can be reasonably predicted, which suggests that morphodynamic evolutions could be simulated without explicitly accounting for consolidation. Replacing the explicit consolidation of the bed by an average erodibility and a critical shear stress for deposition that forces re-erosion of fresh deposits when bottom turbulence is high enough would considerably reduce computing costs of long term simulations. Other tests in 3D configuration should be run in order to confirm this result.

When the bottom mixed sediment is replaced by mud with the same shear strength, results are completely different (Fig. 10d and 10e). Residual erosion rate and SSC are nearly 5 times larger than in the reference case. This is mainly due to the absence of the sand layer that protected the underlying sediment in the reference case. Paradoxically, the sand can be more easily eroded than the mixed sediment below, but this feature is compensated by its constant re-deposition: this is due to the sand large settling velocity, and this constant re-deposition prevents the erosion of underlying sediment as said before. A high turbulence level in the water column is required to reduce this effect (as illustrated during the stormy period on Fig.9d). Using again the concept of bed armouring suggested by Sanford (2008), we propose the idea of dynamic bed armouring, or dynamic interface armouring. This process can be a fundamental feature of mixed sediment, with consequences on sediment fluxes. Its validation therefore has to be addressed with care.

Fig.10e shows realistic variations of concentration in the bed, due to consolidation processes. Mud densification is expectedly faster within fresh deposits, as visible in the upper layers during neap tides or after the storm.

These test-cases illustrate the capacity of the 1DV configuration to explore many features of the model, most of them being related to the sediment behaviour and to the way the layers and their content are managed. The new modelling strategy can also be implemented in a 3D or a 2D depthaveraged model, allowing simulations of sediment transport in a real cases. In all the above tests, the water column was not discretized in order to point out features related to the sediment model capacities only, and to avoid confusing the results. A full 1DV or 3D model could of course be substituted to the depth-integrated water formulation, enabling the simulation of other processes 
such as hindered settling and stratification-induced turbulence damping. This would be required to describe mobile fluid mud layers, and possible feedback on the bed shear stress.

\section{Discussion and conclusion}

The model described in this paper intends to be a modelling framework where different assumptions regarding the sediment behaviour can be tested. As a consequence, the formulation of individual processes can be changed according to new developments regarding these processes, either derived from new measurements or from new theories. For instance, the erosion law of mixed sediments needs more investigation, and its formulation may easily be modified, whether the erosion flux of any class is assumed to be proportional to the class fraction in the surficial sediment or not.

The original features of the model lie in the management of 3 types of particles classes and in the characterization of sediment layers:

- “coarse particles” (first sediment type) influence the consolidation process and other particles erosion rates, but are supposed to be only transported as bedload;

- "sand" (second sediment type, applies to fine and medium sand) is transported in suspension but does not "consolidate";

- "mud" (third sediment type) is also transported in suspension and may consolidate.

The erosion procedure distinguishes two regimes (cohesive or not), depending on the sand/mud ratio. Special attention is paid to the deposition procedure. When material settles, it can either be mixed in the surficial layer, or form a new layer depending on its type and on the composition and the pore content of the upper sediment layer. Within the upper layer, the "filling" process begins with gravel and sand particles up to a maximum concentration that varies according to granular homogeneity; muddy particles are then added to fill the pores between coarser particles, up to an initial unconsolidated concentration. In case deposition of mud occurs on consolidated sediment, a 
new mud layer is created. Consolidation affects the whole sediment thickness, allowing sand segregation whenever the sediment mixture density is low. Thanks to specific precautions when solving the Gibson equation for each sediment class, consolidation can be accounted for whatever the sediment content (e.g. sand layers), the sediment state (e.g. surficial over-consolidation after erosion) and the occurrence of erosion or deposition at the interface. This strategy allows the simulation of sediment layering, as demonstrated in the applications described in this paper.

A short comparison of our modelling strategy to already published process-based numerical models points out the following original features:

- the structure and density of each sediment layer is realistic, including for newly deposits, whatever the distribution of sand and mud; this is essential when accounting for consolidation processes,

- the computation of mixed sediments (sand/mud) consolidation is based on an adapted Gibson equation, and remains operational during erosion or deposition phases,

- in the cohesive regime, the shear strength is parameterized according to the relative mud concentration, which is also used in the effective stress constitutive relationship.

On the other hand, many of our model characteristics can be found in some of the existing models, but none of them includes all these characteristics: the transport of several classes of sand (e.g. Blaas et al., 2007), the distinction of two regimes (cohesive/non cohesive) introduced by van Ledden (2002) and also used by Waeles et al. (2007), the application of Gibson theory for mixed sediments (Toorman and Berlamont, 1993; Toorman, 1996; Merckelbach and Kranenburg, 2004), the extrapolation of sand concentration in the corresponding deposition flux (e.g. Sanford, 2008), the compatibility between consolidation and erosion/deposition processes (Waeles et al., 2007; Sanford, 2008) are examples.

The sediment model is being used either in a 1DV configuration, or in a 3D one. Even in the latter case, given the typical horizontal grid size, processes will be implicitly averaged within each cell of the computation grid, and local heterogeneity can hardly be accounted for. However a stochastic approach of the bed shear strength can be introduced, as long as the distribution of this strength is 
calibrated from observations. This concept was successfully used by van Prooijen and Winterwerp (2010) in order to simulate the so-called supply-limited type of erosion, and could be introduced in the present model. A weakness of the 1DV model formulation is the implicit spreading of all particles within thin sediment layers (often less than $1 \mathrm{~mm}$ thick): in case of a sparse gravel distribution, the corresponding "particles" will be located and spread in a specific layer. This feature should be avoided by setting a minimum layer thickness consistent with the size of the largest sediment class.

Last, the model ignores biotic effects in the sediment. A considerable amount of publications deals with the effects of bioturbation on the sediment. Their analysis should help define dominant or relevant effects both at the water-sediment interface and within the bed; these critical effects should then be integrated within the sediment dynamics model.

The 1DV model was applied to tidal-induced resuspension. Although initially homogeneous, the surficial sediment becomes sorted and a thin layer of sand is formed, covered by mud on slack water or during neap tides. This feature is induced by differences in sand and mud settling velocities. When sheared, the sand layer is easily resuspended, but a large number of sand grains immediately settle, limiting or preventing the resuspension of underlying sediment. As a consequence, the residual erosion rate, as well as the mean suspended sediment concentration, is considerably reduced when sand is mixed with mud, by comparison with results for mud only. This process is called dynamic bed armouring, and deserves a careful experimental validation since consequences on sediment fluxes may be important. More 1DV test cases should also be undertaken, for instance to identify the conditions leading to the formation of mixed layers, in contrast with conditions leading to stratified sediment, both being encountered in natural environments. Additional tests with vertical discretization of the water column are required to consider the specific processes of high-concentration effects occurring right above the bed. But the validation of the new model strategy also supposes several applications to real configurations with mixed sediments, and requires 3D computations. 


\section{References}

Armanini A., 1995. Non-uniform sediment transport: dynamics of the active layer. Journal of Hydraulic Research 33 (5), 611-622.

Blaas M., Dong C., Marchesiello P., McWilliams J.C., Stolzenbach K.D., 2007. Sediment-transport modelling on Southern Californian shelves: a ROMS case study. Continental Shelf Research 27-6, 832-853.

Chesher T.J., Ockenden M.C., 1997. Numerical modelling of mud and sand mixtures. Cohesive Sediments, Burt, Parker and Watts (Eds), John Wiley \& Sons, 395-406.

De Boer G.J., Merckelbach L.M. and J.C. Winterwerp, 2007. A parameterised consolidation model for cohesive sediments. In Estuarine and Coastal Fine Sediment Dynamics, proc. in Marine Science, Elsevier, 243-262.

Dickhudt P., Friedrichs C.T., Sanford L.P., 2010. Mud matrix solids fraction and bed erodibility in the York River estuary, USA, and other muddy environments. Continental Shelf Research, this volume.

Dufois F., 2008. Modélisation du transport particulaire dans le Golfe du Lion en vue d'une application au devenir des traceurs radioactifs issus du Rhône. PhD thesis, Univ. su Sud Toulon Var, 409 p.

Garcia, M., Parker, G., 1991. Entrainment of bed sediment into suspension. Journal of Hydraulic Engineering 117 (4), 414-435.

Gibson R.E., England G.L., \& Hussey M.J.L., 1967. The theory of one dimensional consolidation of saturated clays. Géotechnique 17, 261-273.

Harris, C.K. and Wiberg P.L., 1997. Approaches to quantifying long-term continental shelf sediment transport with an example from the northern California STRESS mid-shelf site. Continental Shelf Research 17, 1389-1418. 
Harris, C.K. and Wiberg P.L., 2001. A two-dimensional, time-dependent model of suspended sediment transport and bed reworking for continental shelves. Computers \& Geosciences 27, 675690.

Hayter E.J., 1986. Estuarial sediment bed model. Estuarine Cohesive sediment Synamics, Ed. Mehta A.J., Springer-Verlag, Berlin, 326-359.

Jacobs W., Le Hir P., van Kesteren W., Cann P., 2010. Erosion threshold of sand-mud mixtures. Continental Shelf Research, this volume.

Le Hir P., Bassoullet P., \& Jestin H., 1989. New developments about mud transport models. Application to a macrotidal estuary. Proc. Int. Symp. Sediment Transport Modeling, New-Orleans, Aug.14-18, 94-99.

Le Hir P. and Karlilow N., 1992. Sediment transport modelling in a macrotidal estuary: do we need to account for consolidation processes? 23 ${ }^{\text {rd }}$ Int. Conf. On Coastal Engineering, ICCE’92, 31213134.

Le Hir P., Ficht A., Silva Jacinto R., Lesueur P., Dupont J.-P., Lafite R., Brenon I., Thouvenin B., Cugier P., 2001a. Fine sediment transport and accumulations at the mouth of the Seine estuary (France). Estuaries 24(6B) 950-963.

Le Hir P., Bassoullet P. and H. Jestin, 2001b. Application of the continuous modelling concept to simulate high-concentration suspended sediment in a macrotidal estuary. In Proceedings in Marine Science Vol.3, Elsevier, 229-247.

Le Hir P., Cann P., Waeles B., Jestin H., Bassoullet P., 2008. Erodibility of natural sediments: experiments on sand/mud mixtures from laboratory and field erosion tests. Sediment and Ecohydraulics: INTERCOH 2005, T. Kusuda, H. Yamanishi, J. Spearman and J.Z. Gailani (Eds), Proceedings in Marine Science 9, Elsevier, 137-153.

Migniot C., 1989. Tassement et rhéologie des vases, 1ère partie. La Houille Blanche 1-1989, 11-29. Merckelbach L.M., 2000. Consolidation and strength evolution of soft mud layers. PhD thesis, Delft Univ. of Technology, 151p. 
Merckelbach L., Kranenburg C., 2004. Equations for effective stress and permeability of soft mudsand mixtures. Geotechnique 54, $\mathrm{N}^{\circ} 4,235-243$.

Neumeier U., Ferrarin C., Amos C.L., Umgiesser G., Li M.Z., 2008. Sedtrans05: an improved sediment-transport model for continental shelves and coastal waters with a new algorithm for cohesive sediments. Computers \& Geosciences 34, 1223-1242.

Panagiotopoulos, I., Voulgaris, G. and Collins, M.B. (1997). The influence of clay on the threshold of movement of fine sandy beds. Coastal Eng., 32:19-43.

Richardson J.F., Zaki, W.N., 1954. The sedimentation of a suspension of uniform spheres under conditions of viscous flow. Chem. Eng. Science, 3, 65-73.

Roberts J., Jepsen R., Gotthard D., Lick, W., 1998. Effects of particle size and bulk density on erosion of quartz particles. Journal of Hydraulic Engineering 124(12), 1261-1267.

Sanchez M., 1992. Modélisation dans un estuaire à mare, rôle du bouchon vaseux dans la tenue des sols sous-marins. Thèse de l’Université de Nantes, 210p.

Sanford L., 2008. Modeling a dynamically varying mixed sediment bed with erosion, deposition, bioturbation, consolidation and armouring. Computers \& Geosciences 34, 1263-1283.

Smith J.D., McLean, S.R., 1977. Spatially averaged flow over a wavy surface. J. Phys. Oceanog. 82 (12), 1735-1746.

Soulsby R., 1997. Dynamics of marine sands: a manual for practical applications. Thomas Telford, 249p.

Teisson C., 1991. Cohesive suspended sediment transport: feasibility and limitations of numerical modelling. Journal of Hydraulic Research, 29, 6, 755-769.

Thiébot J., Guillou S. and Brun-Cottan J.C., 2008. A sedimentation-consolidation model: from parameterisation to validation. Proc. Intercoh’07, submitted to Cont. Shelf Res.

Toorman E.A., Berlamont J.E. (1993). Settling and consolidation of mixtures of cohesive and noncohesive sediments. Advances in Hydro-Science and Engineering. Proc.ICHE’93 (Wang ed.), Univ. of Mississippi, 606-613. 
Toorman E.A. (1996) Sedimentation and self-weight consolidation: general unifying theory. Géoetchnique, 46, 1, 103-113.

Toorman E.A. (1999) Sedimentation and self-weight consolidation: constitutive equations and numerical modelling. Géoetchnique, 49, 6, 709-726.

van Ledden M., 2002. A process-based sand-mud model. In Fine Sediment in the Marine Environment, Winterwerp \& Kranenburg (Eds), Proceedings in Marine Science 5, Elsevier, 577594.

van Ledden M., Wang Z.-B., Winterwerp H., de Vriend H., 2004a.Sand-mud morphodynamics in a short tidal basin. Ocean Dynamics, 54, 385-391.

van Ledden M., van Kesteren W.G.M., Winterwerp J.C., 2004b. A conceptual framework for the erosion of sand-mud mixtures. Continental Shelf Research, 24, 1-11.

van Ledden M., Wang Z.-B., Winterwerp H., de Vriend H., 2006. Modelling sand-mud morphodynamics in the Friesche Zeegat. Ocean Dynamics, 56, 248-265.

van Leussen W., 1994. Estuarine macroflocs and their role in fine-grained sediment transport. PhD thesis of Utrecht University, 488p.

van Prooijen B., Winterwerp J., 2010. A stochastic formulation for erosion of cohesive sediments. Journal of Geophysical Research, 115 C01005, doi:10.1029/2008JC005189.

Van Rijn, L.C., 1985. Sutrench-model: two-dimensional vertical mathematical model for suspended sediment transport by currents and waves. WL|Delft Hydraulics, Report S488, part IV.

Waeles B., Le Hir P., Lesueur P., Delsinne N., 2007. Modelling sand/mud transport and morphodynamics in the Seine river mouth (France): an attempt using a process-based approach. Hydrobiologia (2007) 588: 69-82.

WaelesB., Le Hir P., Lesueur P., 2008. A 3D morphodynamic process-based modelling of a mixed sand/mud coastal environment: the Seine estuary, France. Sediment and Ecohydraulics: INTERCOH 2005, T. Kusuda, H. Yamanishi, J. Spearman and J.Z. Gailani (Eds), Proceedings in Marine Science 9, Elsevier, 477-498. 
Warner J.C., Sherwood C.R., Signell R.P., Harris C.K., Arango H.G., 2008. Development of a three-dimensional, regional, coupled wave, current, and sediment-transport model. Computers \& Geosciences 34, 1284-1306.

Winterwerp J.C., van Kesteren W.G.M, 2004. Introduction to the physics of cohesive sediment in the marine environment. Developments in Sedimentology, Elsevier, 466p.

Winterwerp J.C., 2007. On the sedimentation rate of cohesive sediment. Estuarine and Coastal Fine Sediments Dynamics, Maa, Sanford and Schoellhamer (eds), Proceedings in Marine Science 8, Elsevier, 209-226.

Wu W., Wang S., Jia Y., 2000. Nonuniform sediment transport in alluvial rivers. Journal of Hydraulic Research 38 (6), 427-434. 
Fig 1

[Bedload exchanges and resulting deposition terms]

Erosion of sediment

Computation of erosion fluxes $E_{i}=E_{0}\left(\tau / \tau_{i}-1\right)^{n}$

$E_{0}, \tau_{\mathrm{f}}$ and $n$ depend on surficial sediment

Settling velocity \& deposition tendency

$W_{s t}, \quad C_{i b d} / C_{f 1}=f\left(W_{s i} / u^{*}\right), \quad\left[1-\tau / \tau_{d \dot{d i}}\right]$

Advection/diffusion in water column

$\frac{\partial C_{i}}{\partial}+\vec{U} \cdot g r \vec{a} d C_{i}+W_{s i} \frac{\partial C_{i}}{\partial z}=\frac{\partial}{\partial z} K_{z} \frac{\partial C_{i}}{\partial z}$

Bed exchanges : source: $E_{i}$

$\sin k D_{i}=W_{s i} \cdot\left(C_{i b e d} / C_{i 1}\right) \cdot\left[1-\tau / \tau_{d i}\right] \cdot C_{i 1}$

$C_{i t}$ concentration in the lower ces! $\downarrow$

Deposition in sediment (see fig. 4)

if consolidation :

Computation of permeability and effective stress

Consolidation of sediment layers 
Fig 2

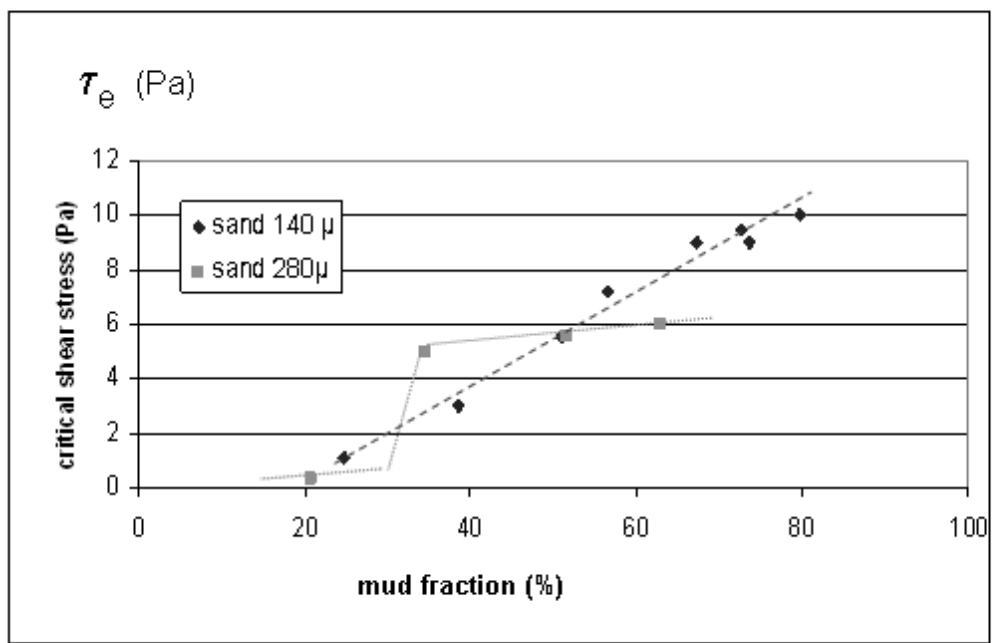


Fig 3

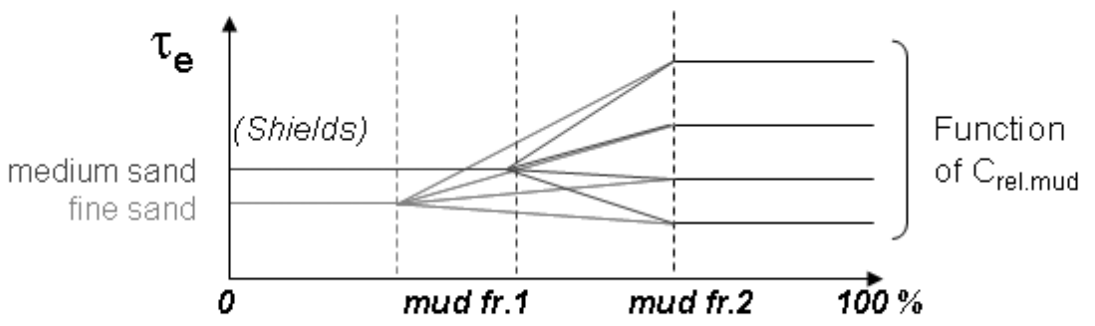


Fig 4a

$C_{\text {rel mud }}$ relative mud concentration of surficial sediment

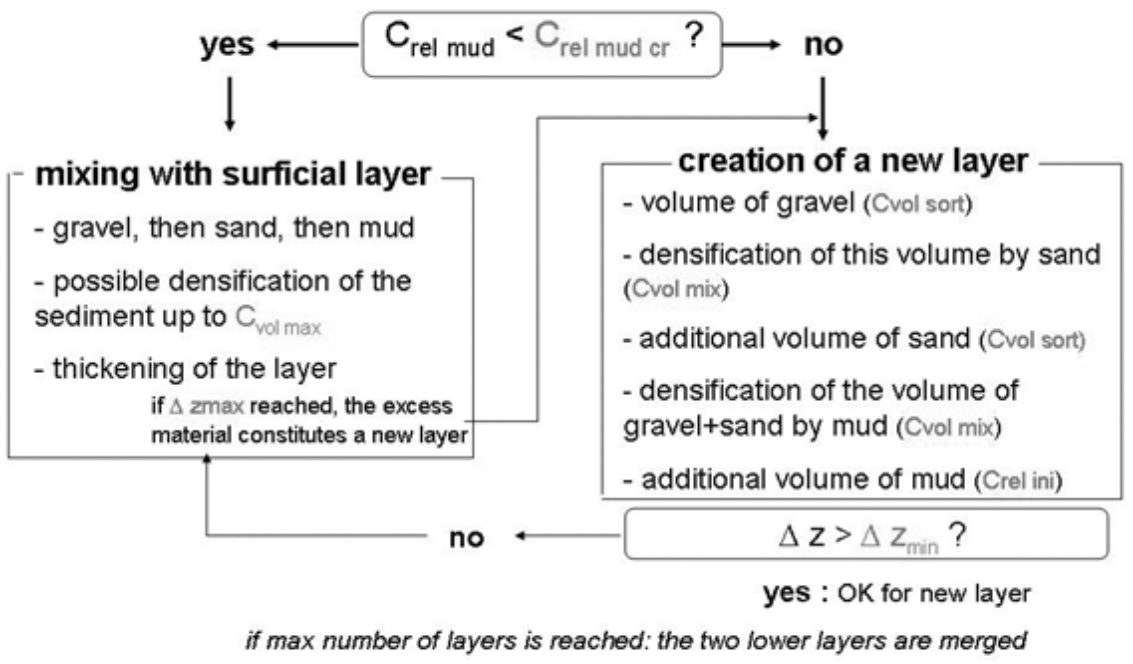


Fig 4b

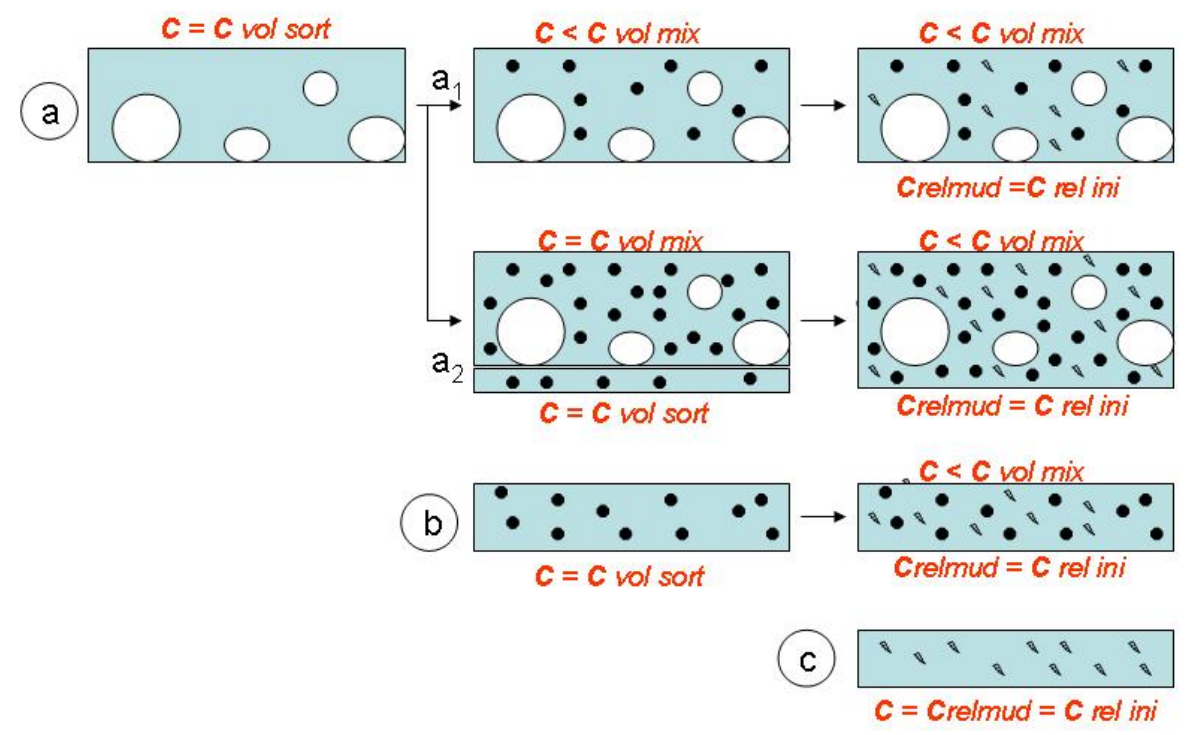


Fig 5

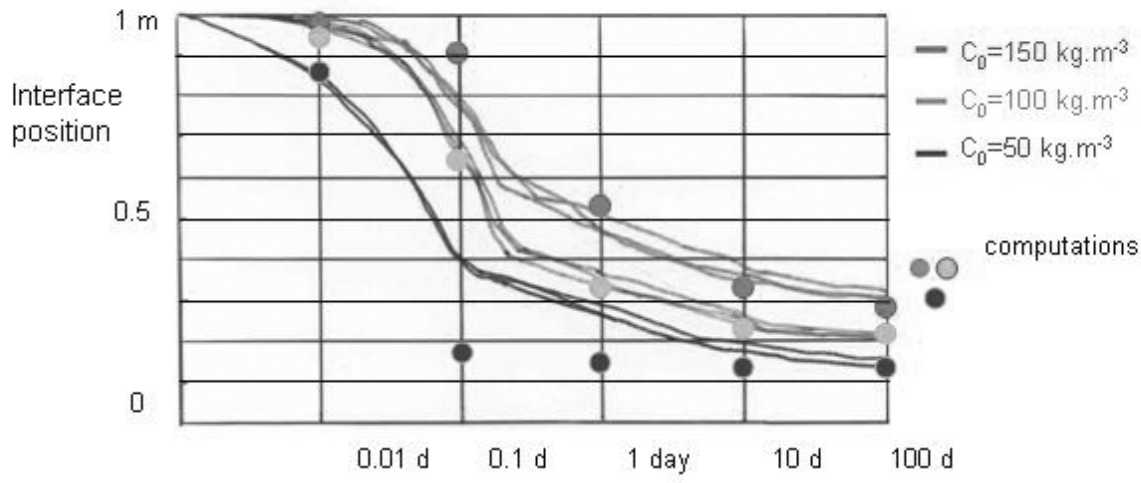


Fig 6
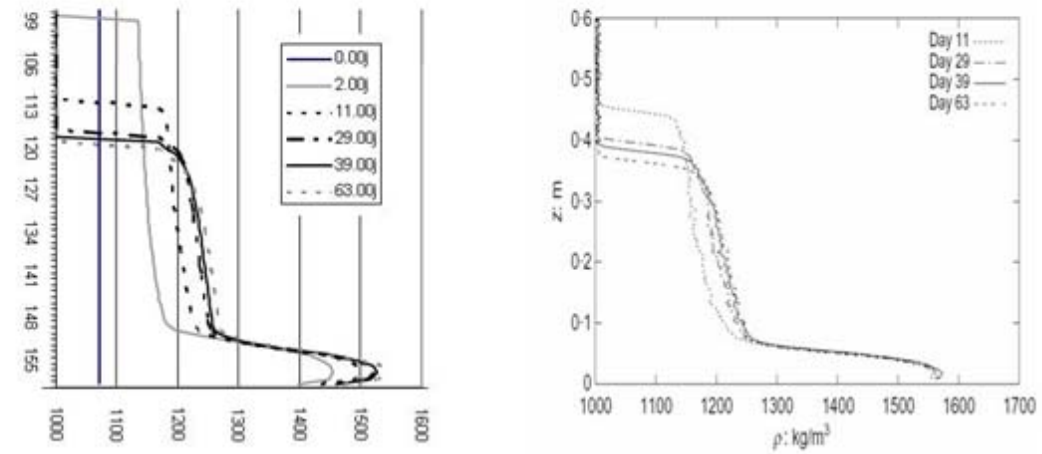
Fig 7
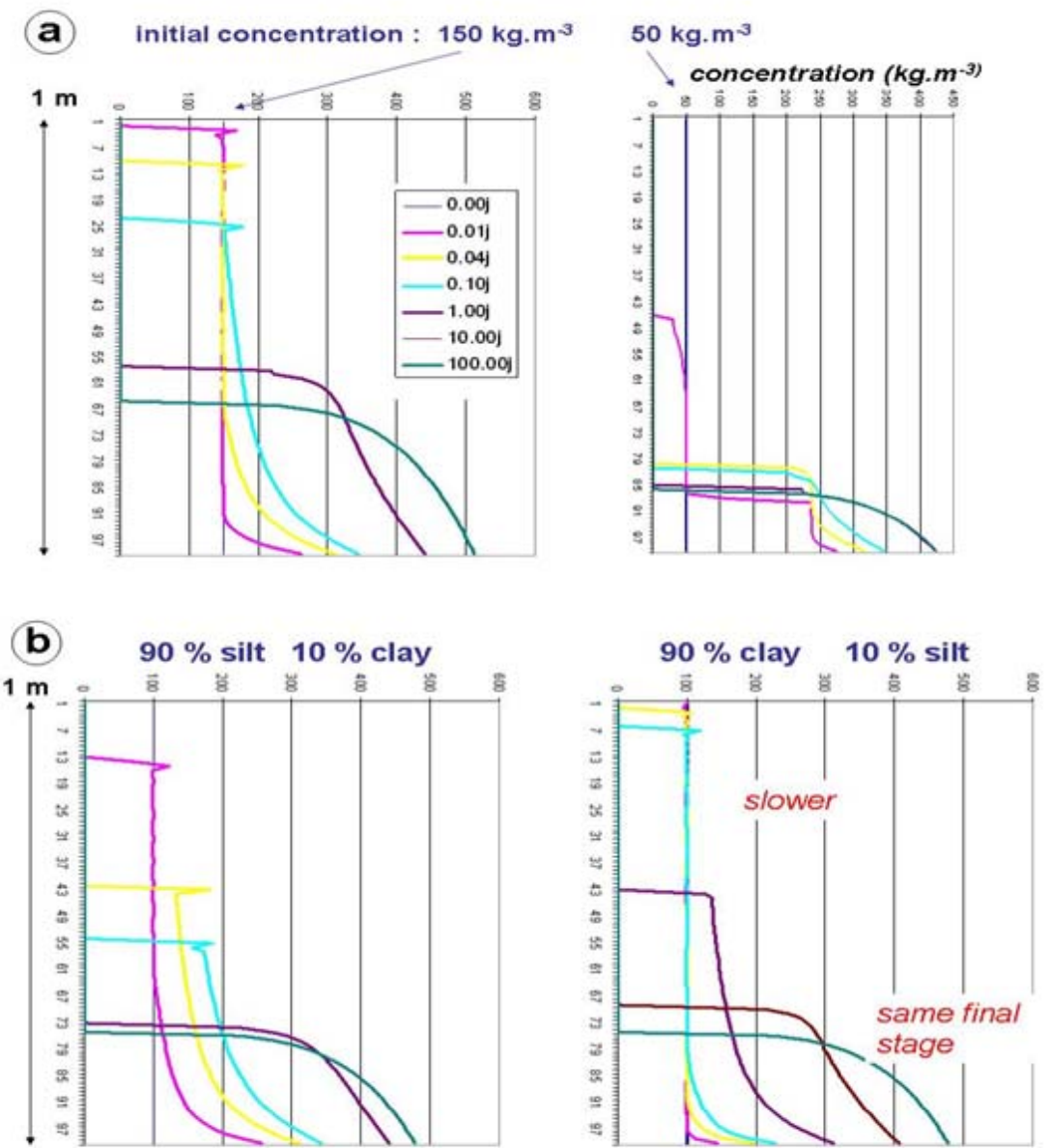

(c)

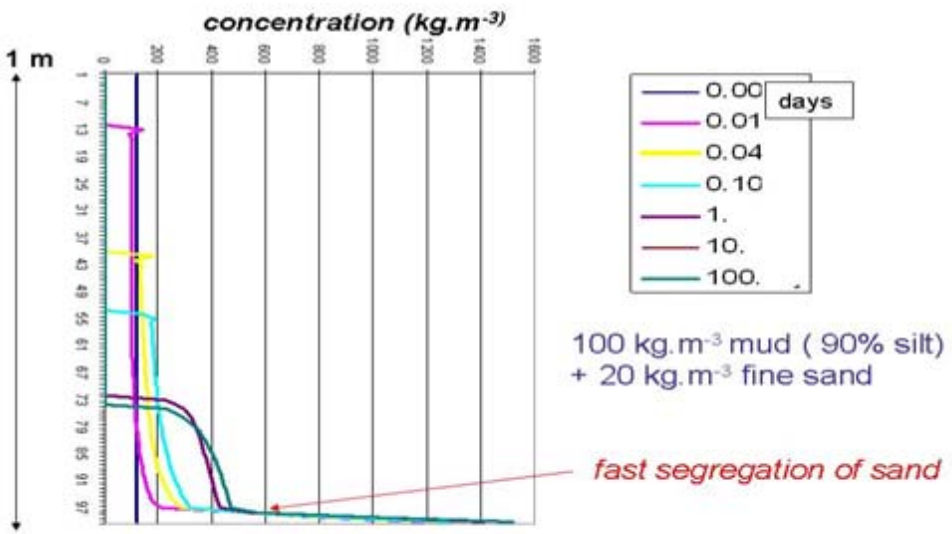


Fig 8

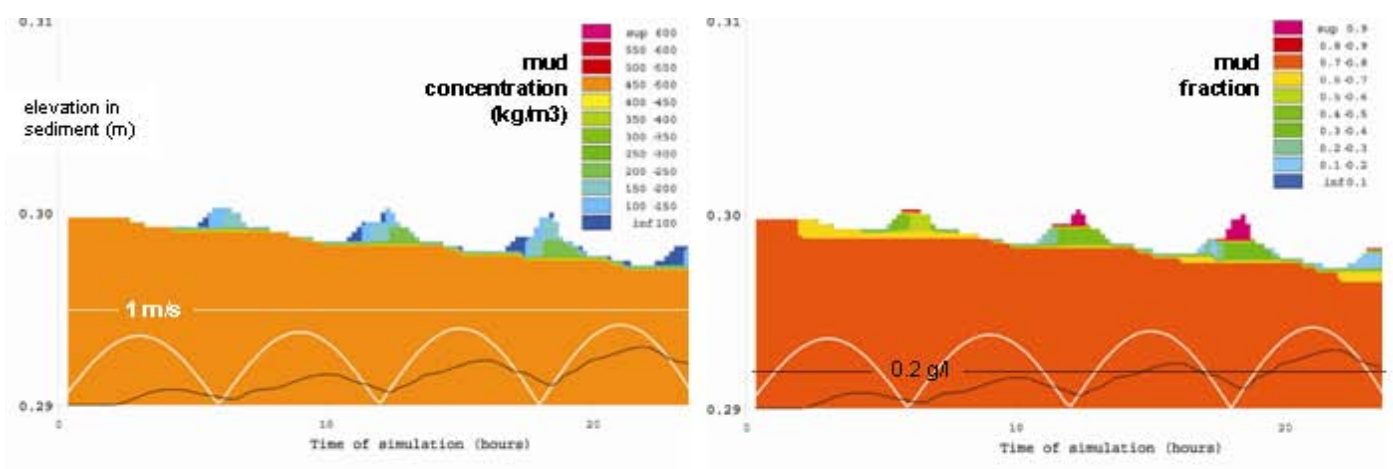


Fig 9

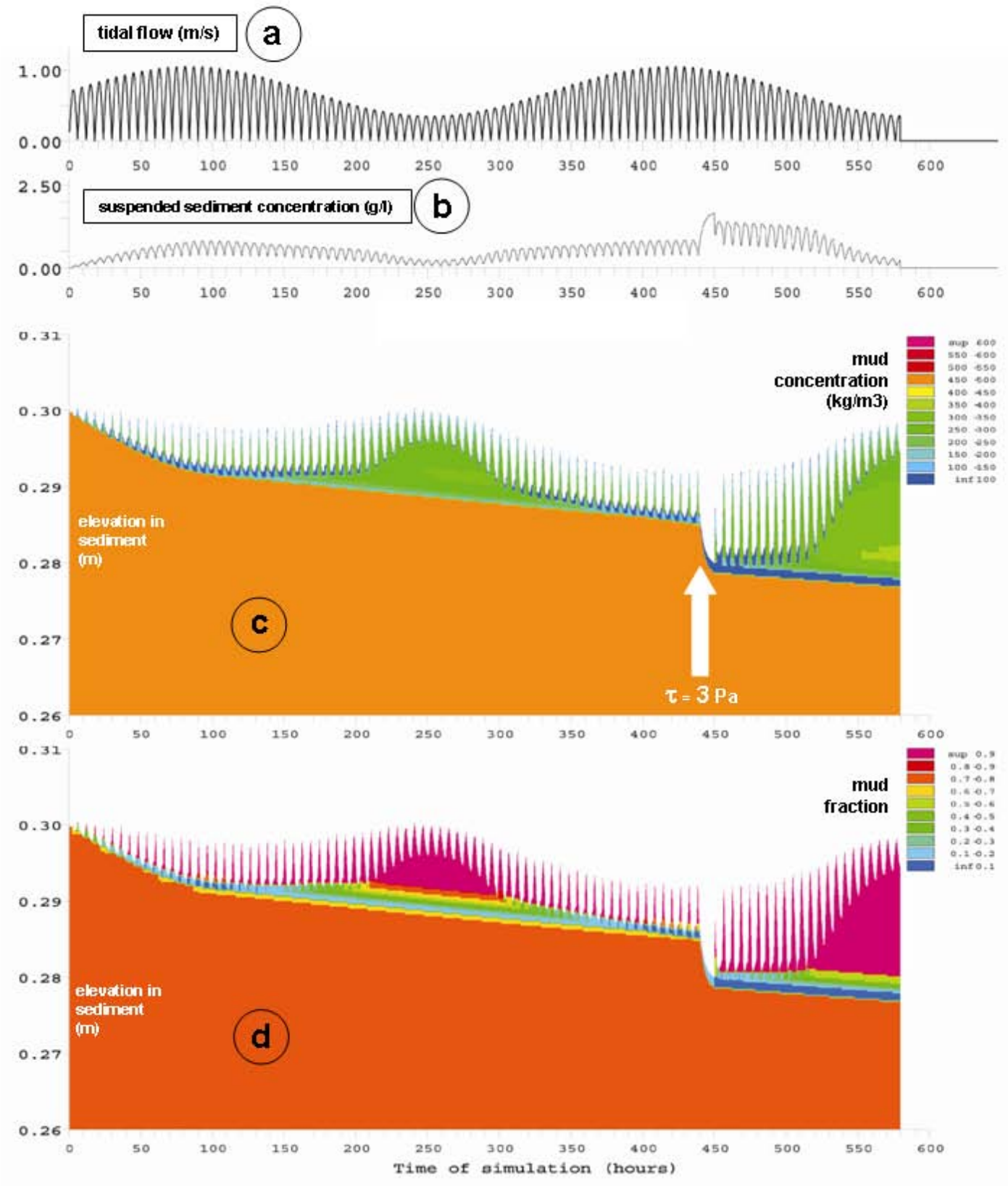


Fig 10
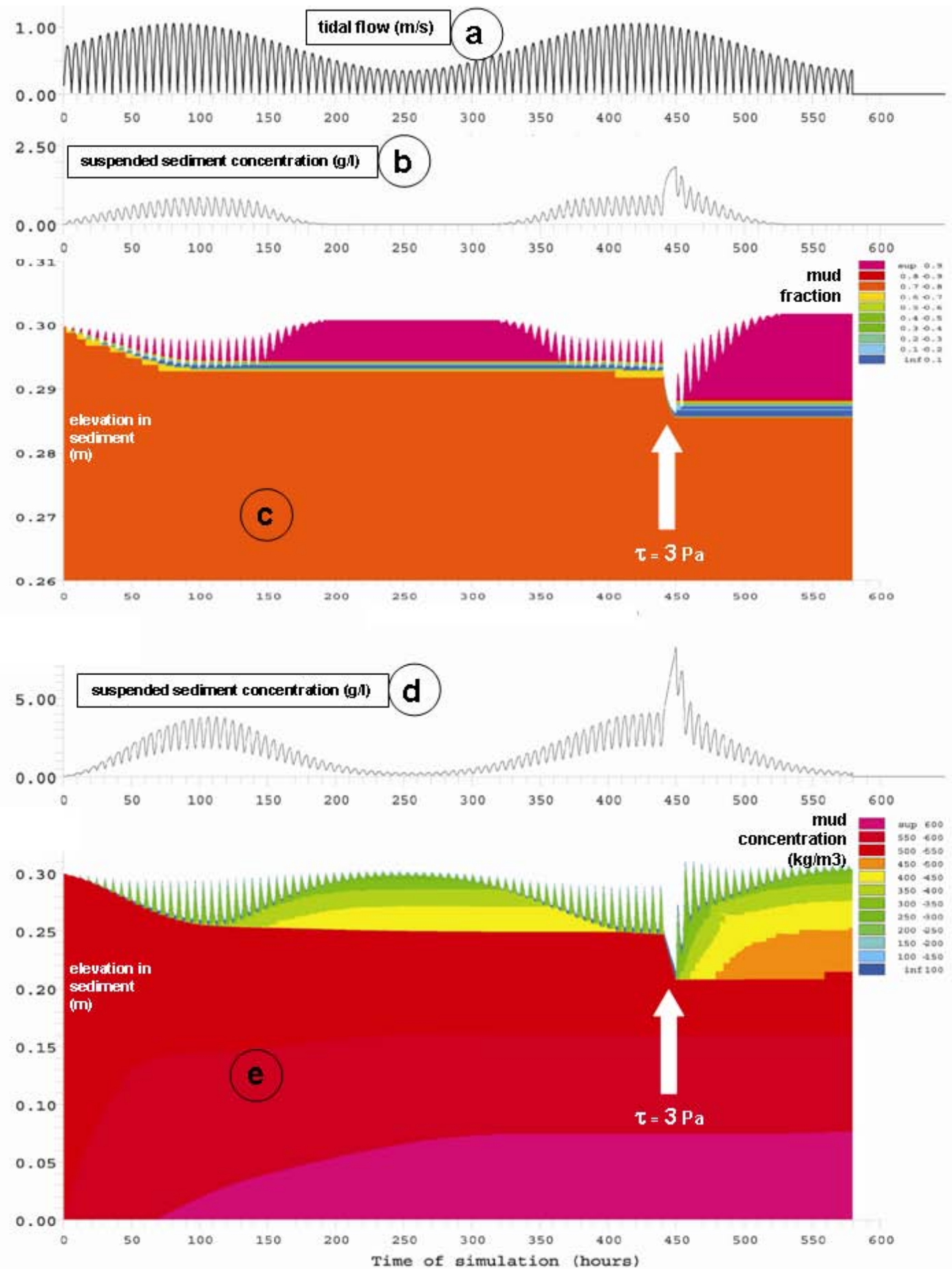
$>$ We present a multilayered mixed sediment (sand + mud) model. $>$ The model respects concentrations for sorted and mixed sediments, it accounts for consolidation $>$ Sand segregation is simulated. > A dynamic bed armouring process is suggested: rapid settling of sand protects underlying sediment. 